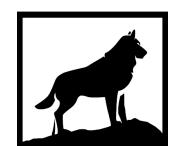

Michigan

Technological

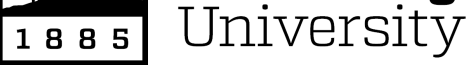

Michigan Technological University

Digital Commons @ Michigan Tech

Dissertations, Master's Theses and Master's Reports

2016

SMALL SIZE COUPLING FEED AND INDUCTIVE SHORTING ANTENNA FOR WIDE BANDWIDTH, INCREASED GAIN AND EFFICIENCY WITH LOW SPECIFIC ABSORPTION RATE (SAR) OPERATION

Md Mahfuzur Rahman

Michigan Technological University, mrahman2@mtu.edu

Copyright 2016 Md Mahfuzur Rahman

Recommended Citation

Rahman, Md Mahfuzur, "SMALL SIZE COUPLING FEED AND INDUCTIVE SHORTING ANTENNA FOR WIDE BANDWIDTH, INCREASED GAIN AND EFFICIENCY WITH LOW SPECIFIC ABSORPTION RATE (SAR) OPERATION", Open Access Master's Thesis, Michigan Technological University, 2016.

https://doi.org/10.37099/mtu.dc.etdr/291

Follow this and additional works at: https://digitalcommons.mtu.edu/etdr

Part of the Electromagnetics and Photonics Commons 


\title{
SMALL SIZE COUPLING FEED AND INDUCTIVE SHORTING ANTENNA FOR WIDE BANDWIDTH, INCREASED GAIN AND EFFICIENCY WITH LOW SPECIFIC ABSORPTION RATE (SAR) OPERATION
}

\author{
By \\ Md Mahfuzur Rahman
}

\begin{abstract}
A THESIS
Submitted in partial fulfillment of the requirements for the degree of MASTER OF SCIENCE

In Electrical Engineering
\end{abstract}

MICHIGAN TECHNOLOGICAL UNIVERSITY

2016

(C) 2016 MD MAHFUZUR RAHMAN 

This thesis has been approved in partial fulfillment of the requirements for the Degree of MASTER OF SCIENCE in Electrical Engineering.

Department of Electrical and Computer Engineering

Thesis Advisor: $\quad$ Dr. Warren F. Perger

Committee Member: Dr. Paul L. Bergstrom

Committee Member: Dr. Ranjit Pati

Department Chair: Dr. Daniel R. Fuhrmann 



\section{Table of Contents}

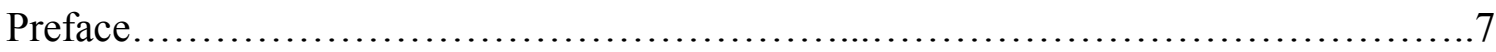

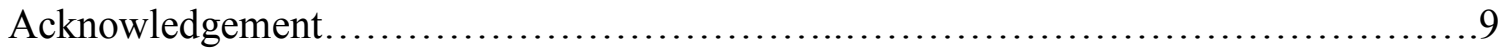

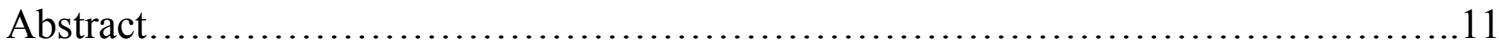

Chapter 1: Introduction..............................................................

Chapter 2: State of the art of the Cell Phone Antenna Techniques........................15

2.1 Microstrip Patch Antenna................................................... 15

2.2 Antenna Feeding Mechanism................................................... 17

2.2.1 Microstrip line feed.................................................. 17

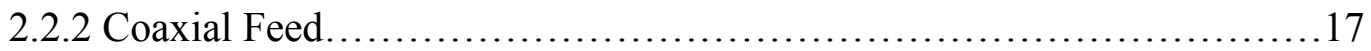

2.2.3 Aperture-coupled feed.............................................. 19

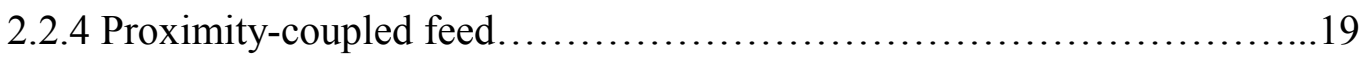

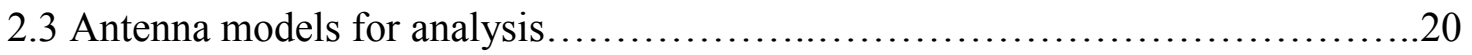

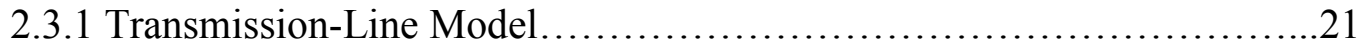

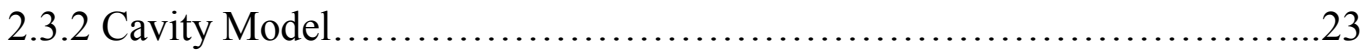

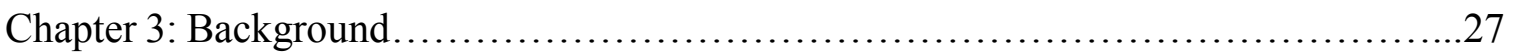

3.1 Scattering Parameter and Reflection coefficient.............................27

3.2 Antenna Quality Factors.................................................. 31

3.3 Antenna Bandwidth ...........................................................

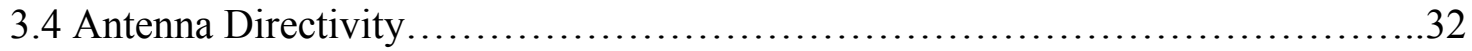

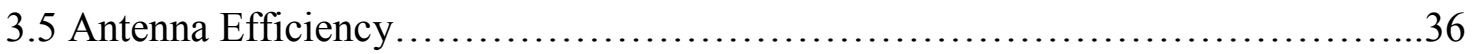

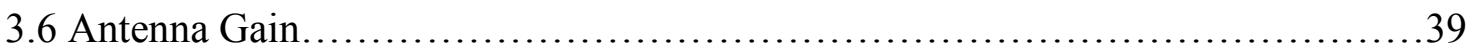

3.7 Specific Absorption Rate (SAR) ................................................ 41

Chapter 4: Proposed Antenna Design Technique.........................................43

Chapter 5: Result and Analysis........................................................ 45

5.1 Surface Current Distribution............................................. 45

5.1.1 Surface Current at Lower Band............................................46

5.1.2 Surface current at upper Band..........................................4 47

5.2 Voltage Standing Wave Ratio (VSWR) Measurement............................48

5.3 Return Loss Measurement....................................................49

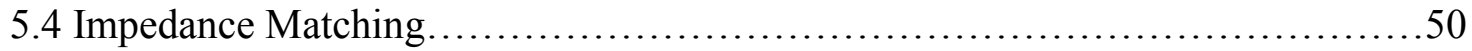


5.5 Radiation Performance................................................ 51

5.5.1 Radiation Pattern...................................................... 51

5.5.1.1 Radiation Pattern at Lower Band....................................51

5.5.1.2 Radiation Pattern at Upper Band...................................52

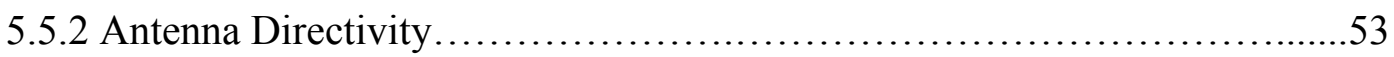

5.5.3 Antenna Gain and Radiation efficiency...............................54

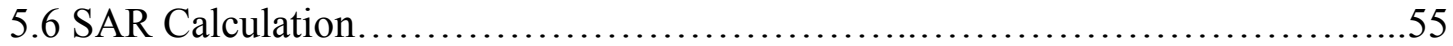

5.6.1 Measured SAR for finite weight biological tissues..........................55

5.6.2 Effect of EM Radiation on human tissues....................................56

Chapter 6: Supplemental Information........................................63

Chapter 7: Conclusion..................................................63

References............................................................65

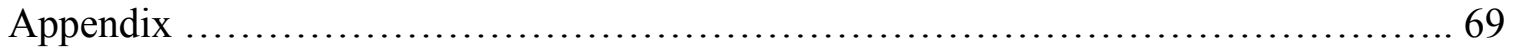

A.1 Evaluation of low dielectric constant Polyimide Aerogel ........................ 69

A.2 Derivation of Specific Absorption Rate for the Electromagnetic Fields effects in

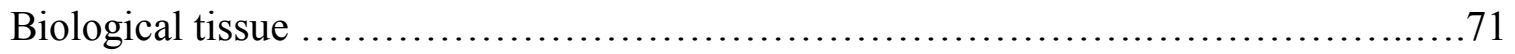

A.3 Permission letter from Mary Ann B. Meador, Sarah Wright, Anna Sandberg, et al, Low Dielectric Polyimide Aerogels as Substrates for Lightweight Patch Antennas, 2012 American Chemical Society 73

A.4 Permission from Panagopoulos DJ, Johansson O, Carlo GL (2013) Evaluation of Specific Absorption Rate as a Dosimetric Quantity for Electromagnetic Fields Bioeffects. PLoS ONE 8(6): e62663. 


\section{Preface}

Technology is changing with time, to cope with the modern technology along with its predecessor mobile phone manufacturers need to implement multiple antennas in a compact space, each serving a specific task. In some 36 months back we started to concentrate our thought to reduce the number of antennas and came up with this novel technique that provide an ultra-wide band operation for mobile phone antenna. We have submitted our manuscript titled as "Ultra-wide band (UWB) polyimide aerogel monopole antenna for wide operations in Ultra High Frequency (UHF) band including ten LTE/GSM/UMTS/WLAN/GPS bands" in IEEE Transactions on Antenna and Propagation few months back on this concept. This thesis is primarily reproduced on the base of our findings from that manuscript.

Chapter 2 and Chapter 3 are based on Constantine a Balanis, Antenna theory - analysis and design (3rd edition), John Wiley \& Sons, Inc. 2005. Appendix A.1 is Reprinted with permission from Mary Ann B. Meador, Sarah Wright, Anna Sandberg, et al, Low Dielectric Polyimide Aerogels as Substrates for Lightweight Patch Antennas, 2012 American Chemical Society (See Appendix A.3 for the reprint permission of this article) whereas Appendix A.2 is reproduced from Panagopoulos DJ, Johansson O, Carlo GL (2013) Evaluation of Specific Absorption Rate as a Dosimetric Quantity for Electromagnetic Fields Bioeffects. PLoS ONE 8(6), June, 2013 (Open Access) 
Page 8 of 74 


\section{Acknowledgement}

I am thankful to my mentors, specially to my advisor Dr. Warren F. Perger, my wife Umme Margia Sultan Honey, my daughter, Jareen Shuva Mreenmoyee and lastly but not least my parents back home in Bangladesh Md Habibur Rahman and Mazeda khatun who has supported me throughout this time span to achieve this degree. 
Page 10 of 74 


\section{Abstract}

Day by day technology is changing our lives rapidly. With these radical changes, demands in communication industry are also increasing drastically. To cope up with these demands, 2G, 3G, 4G, LTE (Long Term Evolution) communication systems have been introduced. Modern cellular phone should be capable to operate in wide range of frequency spectrum for their global access to provide end user customers these communication services. Hence mobile antennas should be designed in such a way that they should generate wideband operation. But commercially available standalone mobile antennas aren't capable to operate in all those communication systems, several antennas are used to get complete communication solution. Different ways have been proposed to obtain wide operation for cellular antennas.

Antenna performance characteristics widely depends on the substrates characteristics and their dimensional specifications. The dielectric constant of the substrate along with the loss tangent greatly influence the antenna performance. Different antenna designs have been proposed with the conventional substrates but these conventional substrate in most cases introduces a cumbersome design specification. Polyimide aerogel with their extreme low dielectric constant and low loss tangent can be used as mobile phone circuit board. Capacitive coupled and inductive shorting monopole antenna can be considered as an RLC circuit that generates multiple resonances which enable wide operation in cellular communications. A simple planar slotted capacitive coupled and inductive shorting monopole antenna along with polyimide aerogel as substrate suitable 
for ten wideband mobile phone operations is presented. These low dielectric constant polyimide aerogel antennas offer wide bandwidth, higher gain and lower mass as compared to the conventional substrate. An ultra-wide band operation is obtained through slotted capacitive coupling feed and inductive shorting of the radiating plate to the ground plate. Capacitive coupling generates high frequency resonance at $1.84 \mathrm{GHz}$ whereas inductive shorting to the ground plate generates low frequency resonance at $780 \mathrm{MHz}$ with an additional resonance at $1.07 \mathrm{GHz}$ due to the effect of higher resonance at $1.84 \mathrm{GHz}$. This proposed antenna covers a wide band $695-2845 \mathrm{MHz}$ that includes ten LTE (LTE700/2300/2500), WWAN (GSM850/900, DCS1800, and PCS1900), GPS and WLAN bands at a 3:1 Voltage Standing Wave Ratio (VSWR). SAR (Specific Absorption Rate) of this proposed antenna is below the SAR standard is presented at the end with the phantom head model. Due to the low dielectric constant of the polyimide aerogel, gain and radiation efficiency are increased while SAR is significantly below the SAR standard for the entire ultra-wide band. 


\section{Chapter 1: Introduction}

In this modern era of cell phone miniaturization, mobile phones with their compact size and their multi-band operation capabilities are in a great demand providing researchers greater interest in antenna designs. These demands of multi-band operation, miniaturization, high efficiency, being lightweight and low specific absorption rate (SAR) inspire researchers to investigate efficient antennas for mobile communication systems [15].

Multi-band operations can be achieved through different antenna structures such as the monopole antenna $[6,7]$, the Planar Inverted-F Antennas (PIFA) [8-11] and loop antenna [12]. Multi-band operation can be generated through the additional resonance by the insertion of a parasitic element, slotting, inductive shorting and capacitive coupling. Capacitively coupled-feed and inductively shorted monopole antennas are widely used in practical mobile phone industries due to their reasonable impedance match, wideband operation, simple structure in nature, comparatively low cost and ease of fabrication [1316]. These antennas with capacitively coupled feed and inductive shorting, resemble an RLC circuit that generates desired resonance for upper and lower bands. Proper dimensioning of these antennas provides improved impedance matching.

A wide planar monopole antenna can generate two wide bands to cover the multiband operations in WWAN (wireless wide area network) communications system $[15,16]$. But these monopole antennas require a large space to accommodate all WWAN bands and the antennas must be folded in a compact area of the mobile phone. This type of a monopole antenna requires a folded radiating structure of size $10 \mathrm{~mm} \times 10 \mathrm{~mm} \times 70 \mathrm{~mm}\left(7.0 \mathrm{~cm}^{3}\right)[15]$ 
or $10 \mathrm{~mm} \times 15 \mathrm{~mm} \times 35 \mathrm{~mm}\left(5.25 \mathrm{~cm}^{3}\right)$ [16] for WWAN band operation. Moreover, these folded monopole antennas require a radiating plate thickness of $10 \mathrm{~mm}$. This is typically not feasible in the present-day mobile phone applications. Internal antennas in modern cellular phones should have a low profile of $4 \mathrm{~mm}$ or less.

In this article, we present a slotted capacitively coupled feed and inductively shorted monopole antenna that covers ten LTE (Long Term Evolution)/WWAN (Wireless Wide Area Network)/GPS (Global Positioning System)/WLAN (Wireless Local Area Network) bands- three LTE bands, LTE700(698-787 MHz), LTE2300 (2305-2400 MHz), LTE2500 (2500-2690 MHz); four GSM (Global System for Mobile communication) bands, GSM850 (824-894 MHz), GSM900 (890-960 MHz), DCS1800 (Digital Communication System, 1710-1880MHz), PCS1900 (Personal Communication System, 1850-1990 MHz); UMTS (Universal Mobile Telecommunication System, 19202170MHz); GPS (1575.42MHz) and WLAN2.4 (2400-2484MHz) band. Antenna characteristics widely depend not only on antenna size, but also on other antenna parameters such as the size of the ground plane, type of the radiating plate, substrate, etc. In [2] Liang et al present a small LTE/WWAN antenna buts it requires a ground plate of $115 \mathrm{~mm} \times 60 \mathrm{~mm}\left(6900 \mathrm{~mm}^{2}\right)$. In our proposed antenna we introduce a ground plate of only $100 \mathrm{~mm} \times 40 \mathrm{~mm}$ while the total dimension of the system circuit board is $130 \mathrm{~mm} \times 40 \mathrm{~mm}$ $\left(5200 \mathrm{~mm}^{2}\right)$. Our proposed antenna is much simpler and the overall dimensions of our antenna are smaller compared with [2]. 


\section{Chapter 2: State of the art of the Cell Phone Antenna Techniques}

\subsection{Microstrip Patch Antenna}

In general, a microstrip patch antenna is etched on one side of a two sided coated dielectric substrate and other side of the substrate is used as a ground plane as shown in Figure 2.1. The coated layers are usually made of conducting material and most common coated layers in today's industries are with copper and gold. The feed lines and the radiating patch both are generally photo etched on the dielectric substrate. The patch antennas are widely used due to their low cost, light weight and low volume, ease on fabrication, mechanically robust when mounted on rigid surfaces, easy integration with microwave integrated circuits (MICs) and conformity both with planar and nonplanar surfaces. Even though microstrip patch antennas suffer from the low efficiency, low bandwidth, low power handling capacity, high quality factor Q (even sometime greater than 100), poor polarization purity, spurious feed radiation, unwanted radiation from feeds and junctions and surface wave generation [17]. 


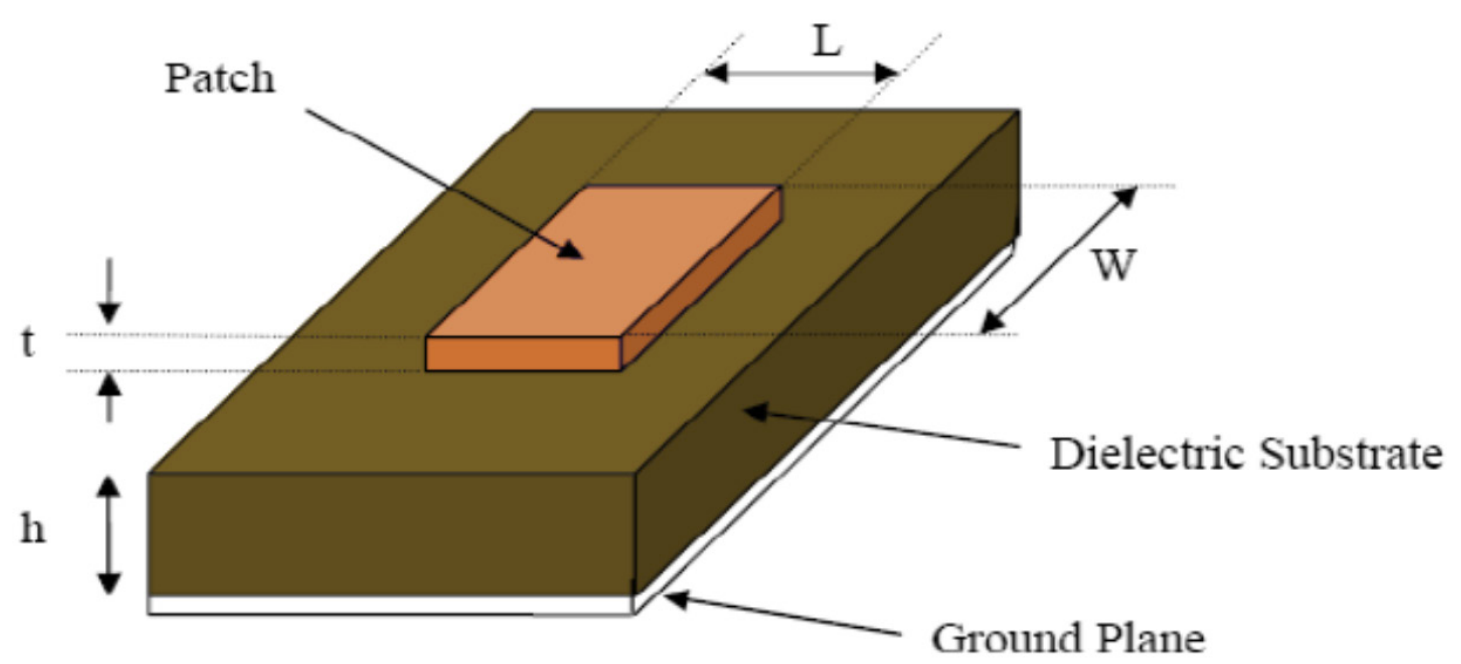

Figure 2.1: Physical geometry of the Patch Antenna

In microstrip patch antenna radiation occurs between patch and the ground plane due to the fringing fields between them. A low dielectric constant substrate is desirable for wider bandwidth and higher efficiency. But dielectric constant of the substrate is inversely proportional to its thickness, hence a thick dielectric substrate with a low dielectric constant is required for better antenna performances. This thick substrate hinders the progress of antenna implementation in a compact space. Again substrate with higher dielectric constant have narrower bandwidth and lower efficiency and not desirable in practical condensed antenna structure. Hence antenna parameters must be chosen with a trade-off between the antenna performance and its dimensions. 


\subsection{Antenna Feeding Mechanism}

There are various techniques available to feed microstrip antenna, among them (a) Microstrip line feed (b) Coaxial feed (c) Aperture-coupled feed and (d) Proximity-coupled feed are widely used in antenna analysis [17].

\subsubsection{Microstrip line feed}

In this technique, a conducting strip is used to feed the microstrip patch antenna. Microstrip feed line is also photo etched on the substrate as the same was as with the patch antenna. The width of the microstrip feed line is narrower than the width of patch antenna. Microstrip antenna provides better impedance matching without any additional matching circuit and impedance matching is achieved through the positioning of the microstrip feed. Its an easy feeding technique and easy to fabricate. It provides unwanted radiation from the microstrip feed line.

\section{Microstrip Feed}

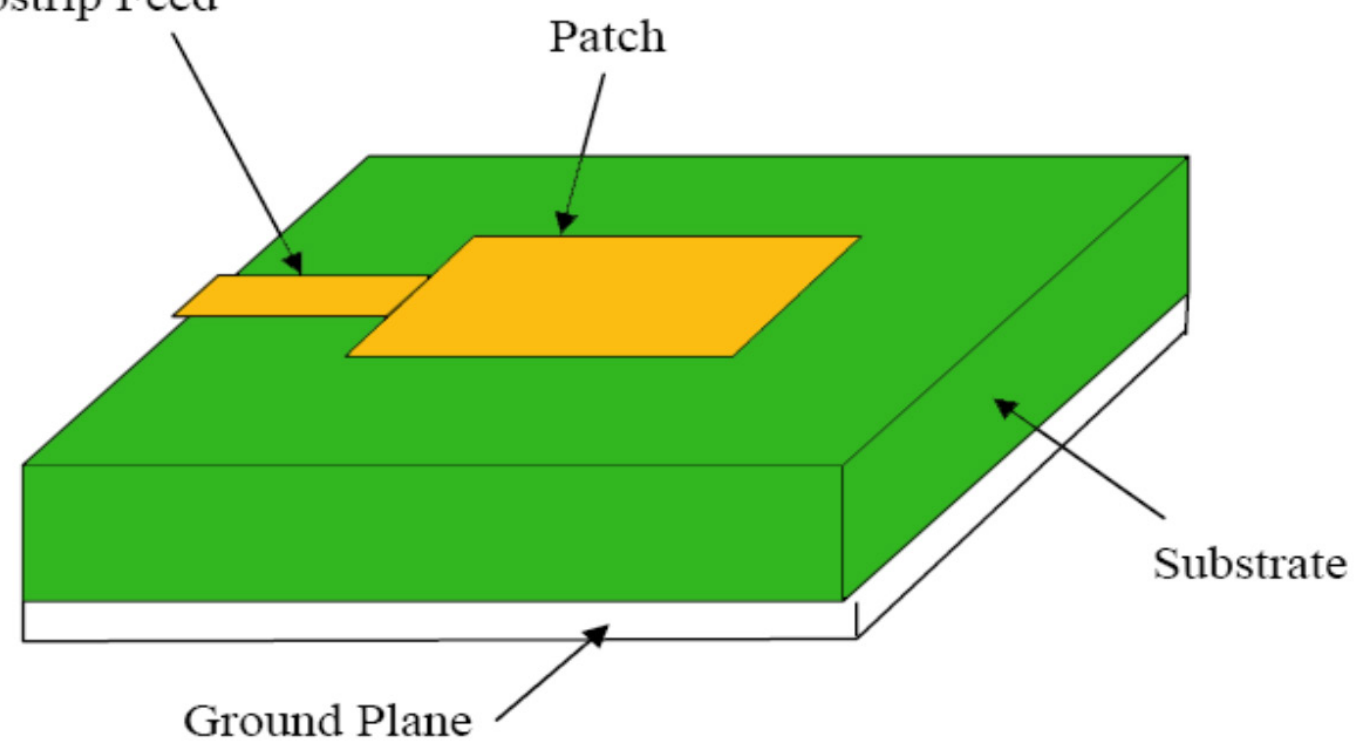

Figure 2.2: Microstrip line feeding for the Patch

\subsubsection{Coaxial Feed}

In this technique, patch antenna is excited through the coaxial cable, inner conductor of the coaxial cable is soldered to the patch antenna where the outer conduct is soldered to the ground plane. The feeding probe can be placed at any place to achieve better impedance 
matching. It has less spurious radiation as compared to microstrip line feed discussed above. Nonetheless this coaxial feed technique has narrow bandwidth and more challenging to handle as a hole has to be drilled through the substrate.
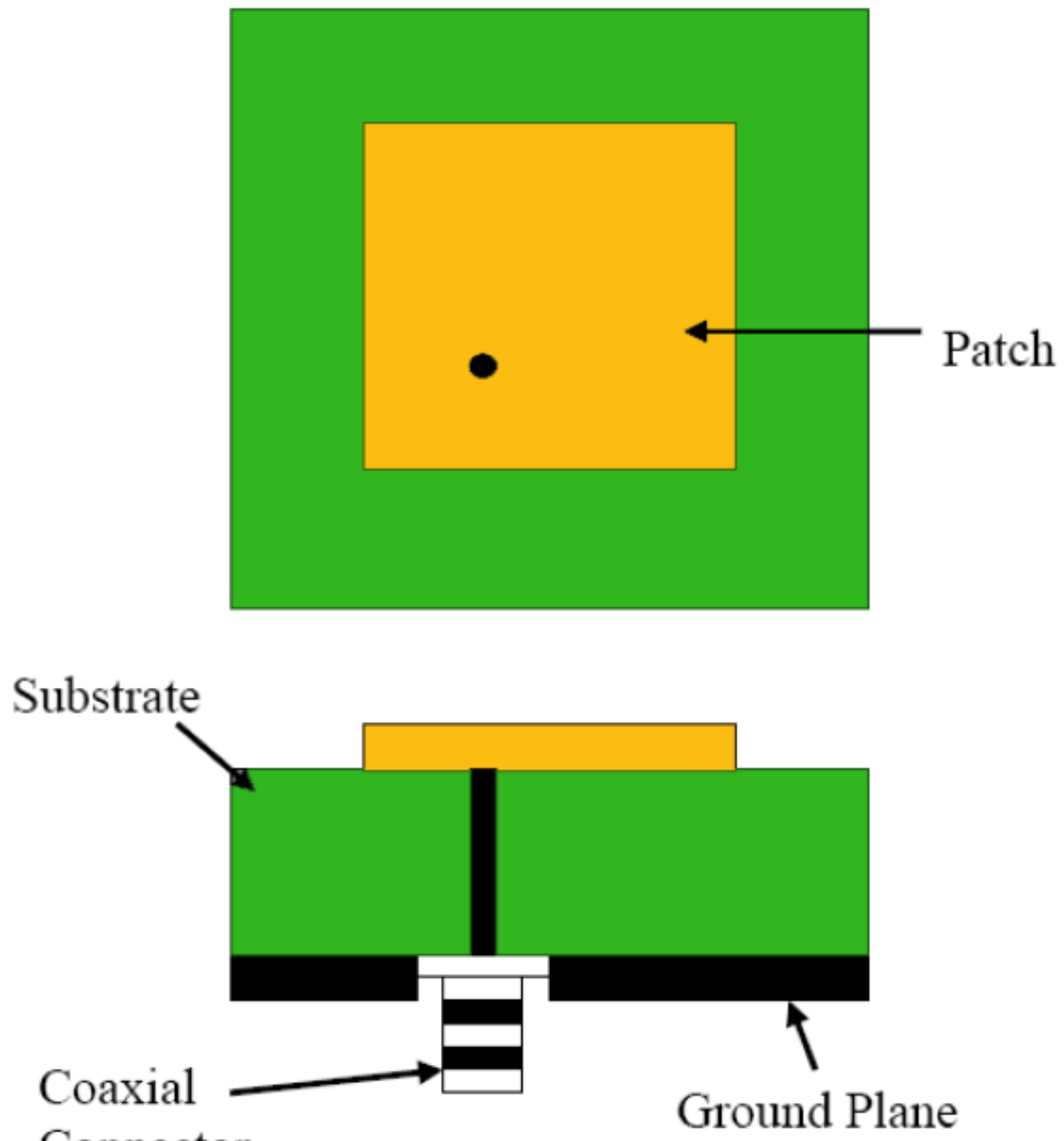

Connector

Figure 2.3: Coaxial cable feeding for the Patch Antenna 


\subsubsection{Aperture-coupled feed}

In this technique, two substrates are used separated by the ground plane. Microstrip feed is etched on the bottom side of the lower substrate while microstrip patch is etched on the top surface of the top substrate. The excitation energy from the feed is coupled to the patch through the hole in the ground plane. Among all these four feeding mechanism aperture-coupled feed is the most difficult feeding technique. Both the microstrip feed and the coaxial feed produce higher order modes that in turn generates cross-polarized radiation. To overcome this cross-polarized radiation aperture-coupled feed is used in antenna analysis.

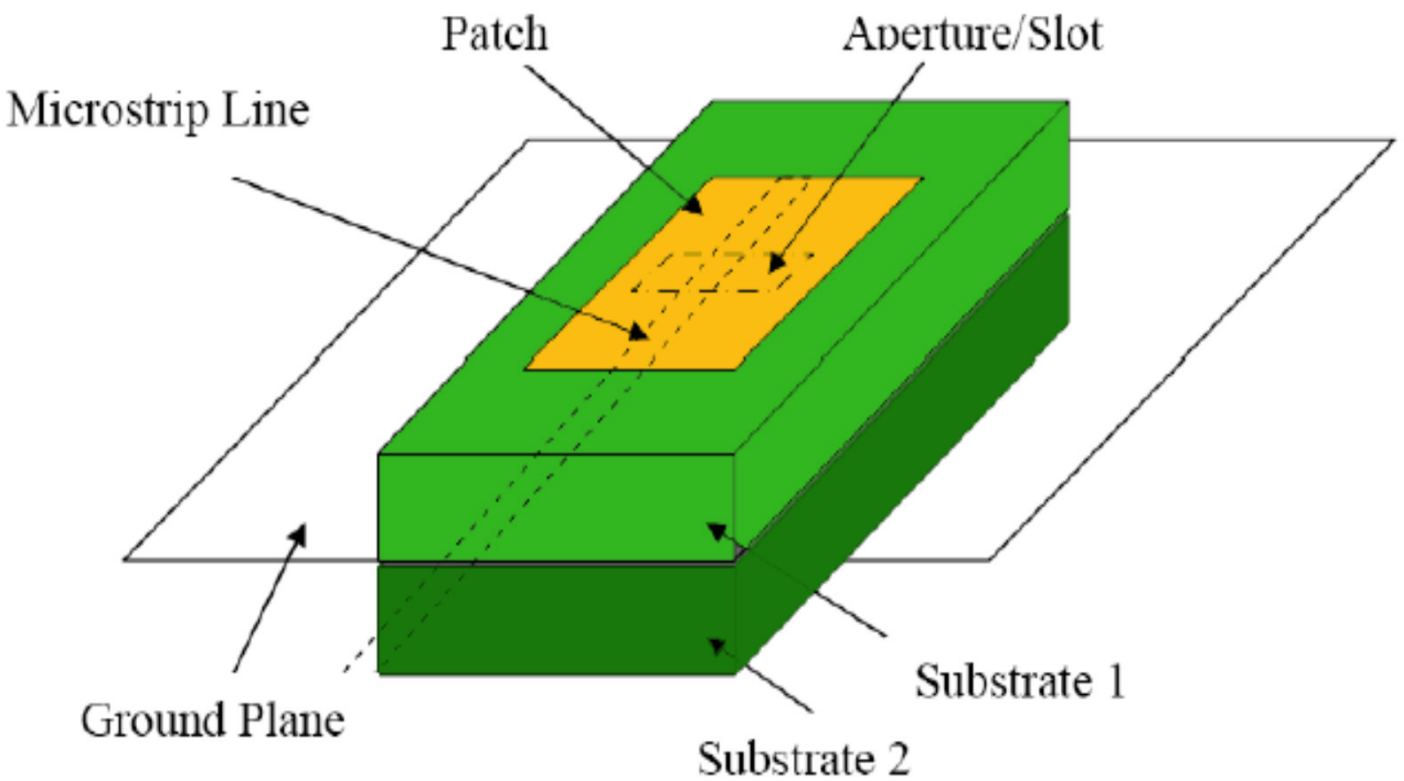

Figure 2.4: Aperture coupled feeding for the Patch antenna

\subsubsection{Proximity-coupled feed}

In this technique two substrates are used, microstrip feed line is in between of these two substrate where patch is etched on top of the upper substrate. Its difficult to fabricate as 
these two substrates need to aligned, has reduced spurious feed radiation but has comparatively higher bandwidth. Matching of this proximity-coupled feed is achieved through the adjustment of the length and width of the microstrip feed and width to length ratio of the microstrip patch.

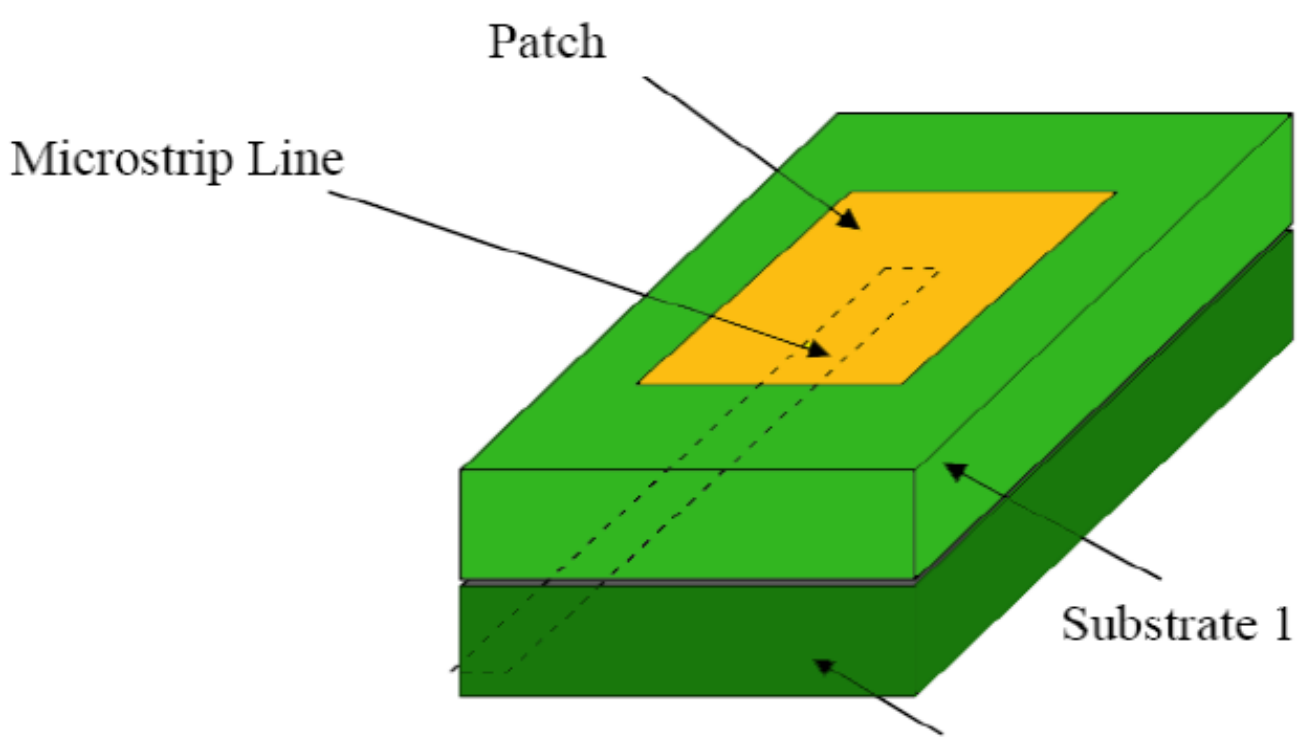

Substrate 2

Figure 2.5: Proximity-coupled feeding for the Patch Antenna

\subsection{Antenna models for analysis}

The microstrip patch antennas can be investigated through different antenna techniques. The most common models are the transmission-line model, cavity model and full wave model. The transmission line prototype is the simplest model that offers perfect geometrical understanding of the antenna but measured data are less precise. Cavity prototype is somewhat byzantine prototype as compared to transmission line prototype and data are further precise than transmission line prototype. Cavity prototype also offers better geometrical understanding of the antenna. Whereas full-wave prototypes are constructed through complicated integral equations, offer less geometrical understanding. While the full-wave prototypes can handle any formed structures and data are very accurate. 


\subsubsection{Transmission-Line Model}

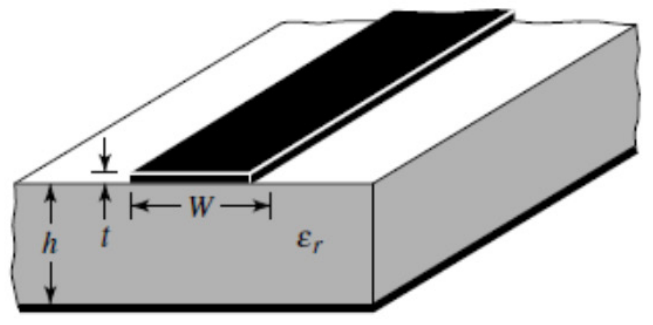

(a) Microstrip line

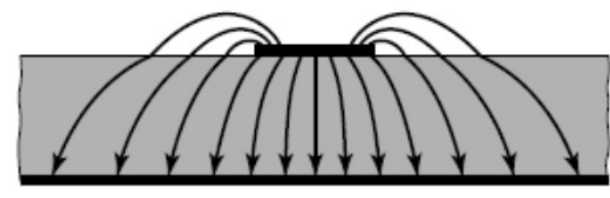

(b) Electric field lines

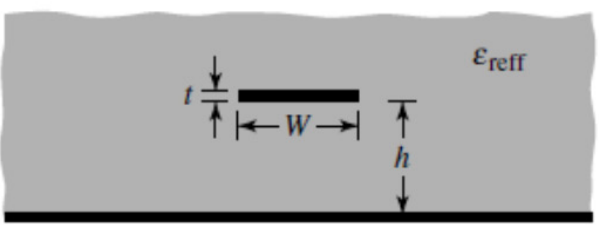

(c) Effective dielectric constant

Figure 2.6: Microstrip line and its electric field lines, and effective dielectric constant geometry.

The field lines radiated from the edges of the patch of the antenna experience fringing effect those are illustrated in Figure 2.6 (b). The magnitude of the fringing effect depends on the dimension of the patch and the width of the substrate. Due to this fringing effect effective dielectric constant of the substrate is reduced from its actual value while effective length is increased for fringing radiation from the two radiating slots along the width. 


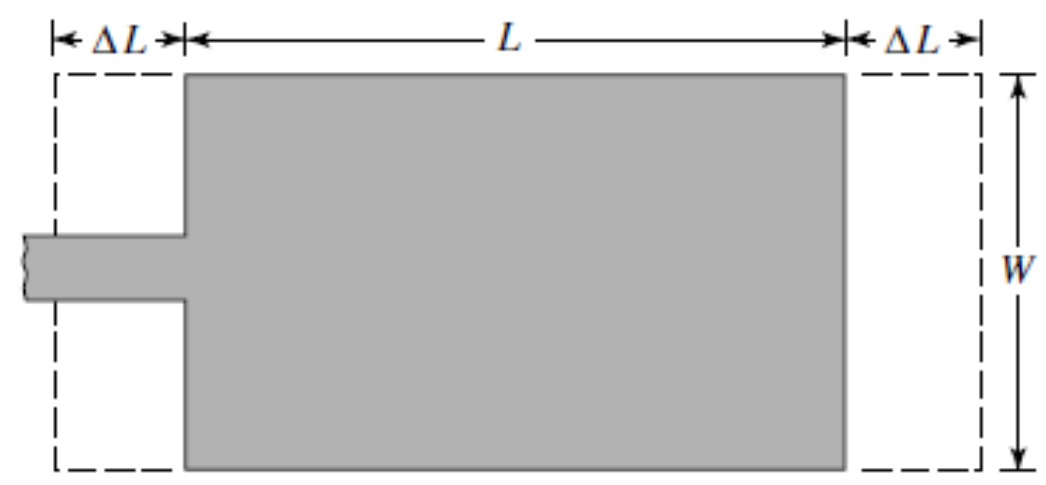

(a) Top view

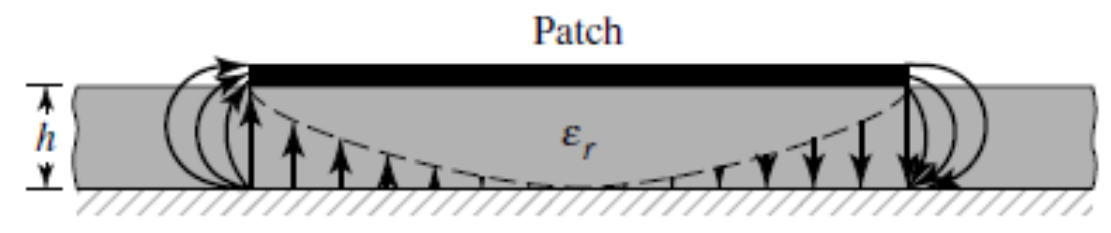

(b) Side view

Figure 2.7: Effective length of the patch due to fringing fields

To design patch we need to specify our resonance frequency $\left(f_{r}\right)$, width of the substrate (h) and dielectric constant of the substrate $\left(\epsilon_{r}\right)$.

Step 1: Patch width calculation

$$
W=\frac{1}{2 f_{r} \sqrt{\mu_{0} \epsilon_{0}}} \sqrt{\frac{2}{\epsilon_{r}+1}}=\frac{v_{0}}{2 f_{r}} \sqrt{\frac{2}{\epsilon_{r}+1}}
$$

Step 2: Effective permittivity calculation

$$
\epsilon_{\text {reff }}=\frac{\epsilon_{r}+1}{2}+\frac{\epsilon_{r}-1}{2}\left[1+12 \frac{h}{W}\right]^{-1 / 2}
$$


Step 3: Length increase due to fringing effect

$$
\frac{\Delta L}{h}=0.412 \frac{\left(\epsilon_{\text {reff }}+0.3\right)\left(\frac{W}{h}+0.264\right)}{\left(\epsilon_{\text {reff }}-0.258\right)\left(\frac{W}{h}+0.8\right)}
$$

Step 4: Effective length calculation

$$
L_{e f f}=\frac{1}{2\left(f_{r c}\right)_{010} \sqrt{\epsilon_{r e f f}} \sqrt{\mu_{0} \epsilon_{0}}}=\frac{v_{0}}{2\left(f_{r c}\right)_{010} \sqrt{\epsilon_{\text {reff }}}}
$$

Step 5: Actual length of the patch

$$
L_{\text {actual }}=L_{\text {eff }}-2 \Delta L
$$

\subsubsection{Cavity Model}

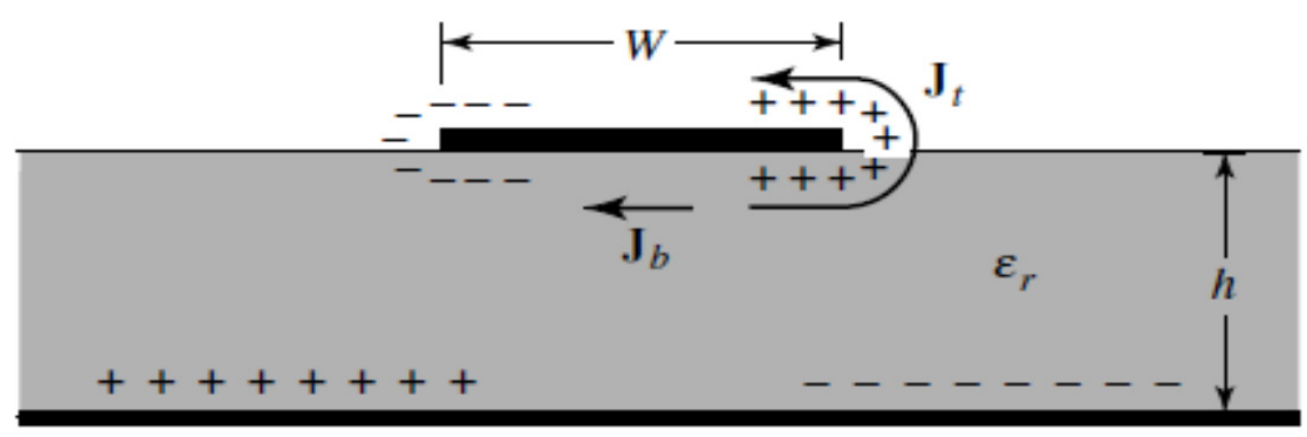

Figure 2.8: Charge distribution and current density creation on microstrip patch. 
The volume beneath the patch can be treated as a rectangular cavity loaded with a dielectric material with dielectric constant $\varepsilon_{\mathrm{r}}$. When the patch is excited, a charge distribution is realized on the top surface of the ground plate as well as the bottom surface of the patch as shown in figure 2.8. This charge distribution is due to the attractive forces between opposite charges in those surfaces. There is another mechanism- repulsive forces between the same charges that forces some charges to move from bottom surface to the top surface of the patch. These flow of charges are represented through the current densities $\mathrm{J}_{\mathrm{b}}$ and $\mathrm{J}_{\mathrm{t}}$.

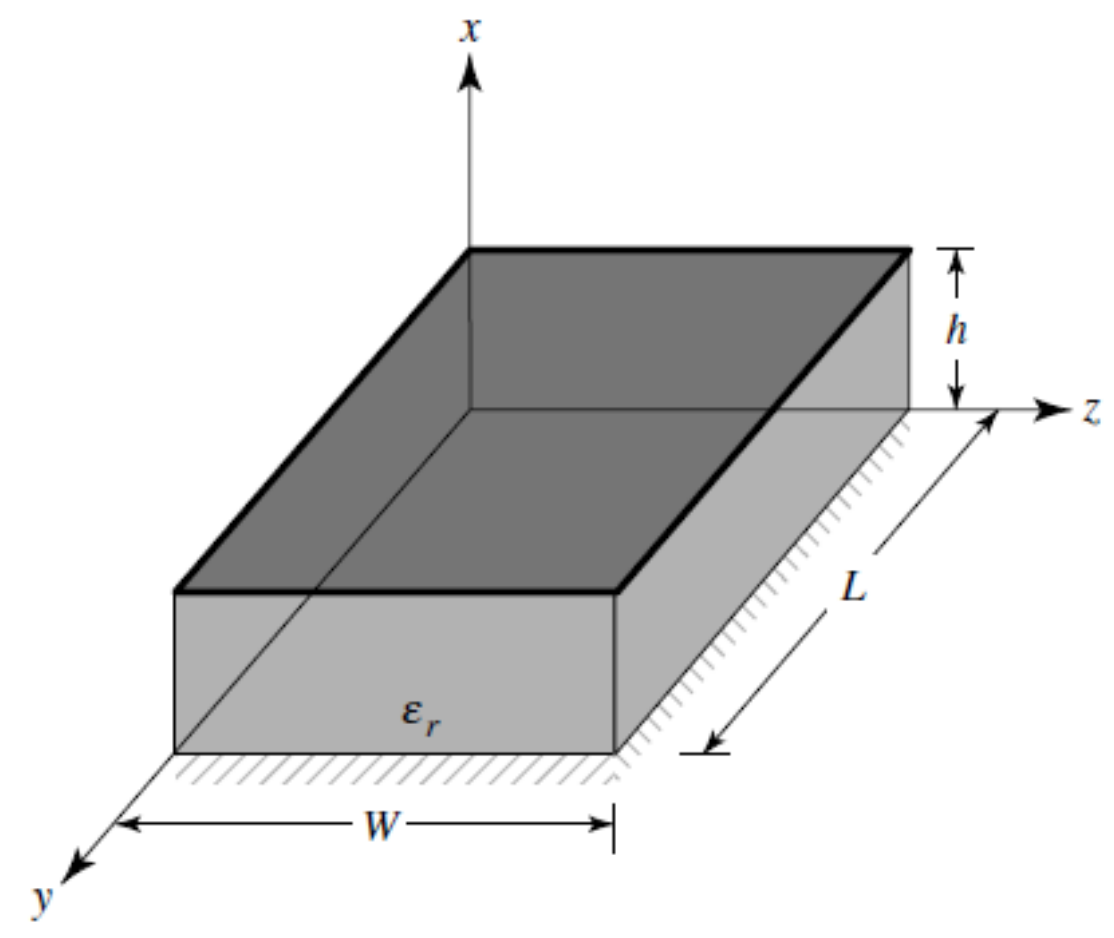

Figure 2.9: Dielectric material loaded cavity model for the Patch antenna

Due to very thin dielectric substrate as compared to its length $(h / L \ll 1)$, fringing fields from the edges of the substrate can be neglected. Hence $T M^{x}$ fields are realized within the cavity whereas electric fields are almost perpendicular to the patch. The top and bottom surfaces can be considered as perfect electric conductors and other four surrounding walls are treated as perfect magnetic conductors. 
The resonant frequencies for the cavity are given by

$$
\left(f_{r}\right)_{m n p}=\frac{1}{2 \pi \sqrt{\mu \epsilon}} \sqrt{\left(\frac{m \pi}{h}\right)^{2}+\left(\frac{n \pi}{L}\right)^{2}+\left(\frac{p \pi}{W}\right)^{2}}
$$

where $\mathrm{m}, \mathrm{n}, \mathrm{p}$ represent, respectively, the number of half-cycle field variations along the $\mathrm{x}, \mathrm{y}, \mathrm{z}$ directions.

If $\mathrm{L}>\mathrm{W}>\mathrm{h}$, lowest order resonance frequency (dominant mode) for the $T M_{010}^{x}$ mode is

$$
\left(f_{r}\right)_{010}=\frac{1}{2 L \sqrt{\mu \epsilon}}=\frac{v_{0}}{2 L \sqrt{\epsilon_{r}}}
$$

where $v_{0}$ is the speed of light in free-space.

If $\mathrm{L}>\mathrm{W}>\mathrm{L} / 2>\mathrm{h}$, the next higher order (second) mode is the $T M_{001}^{x}$ whose resonant frequency is given by

$$
\left(f_{r}\right)_{001}=\frac{1}{2 W \sqrt{\mu \epsilon}}=\frac{v_{0}}{2 W \sqrt{\epsilon_{r}}}
$$

If $\mathrm{L}>\mathrm{L} / 2>\mathrm{W}>\mathrm{h}$, then the second higher order mode is the $T M_{020}^{x}$ and its resonance frequency is given by

$$
\left(f_{r}\right)_{020}=\frac{1}{L \sqrt{\mu \epsilon}}=\frac{v_{0}}{L \sqrt{\epsilon_{r}}}
$$




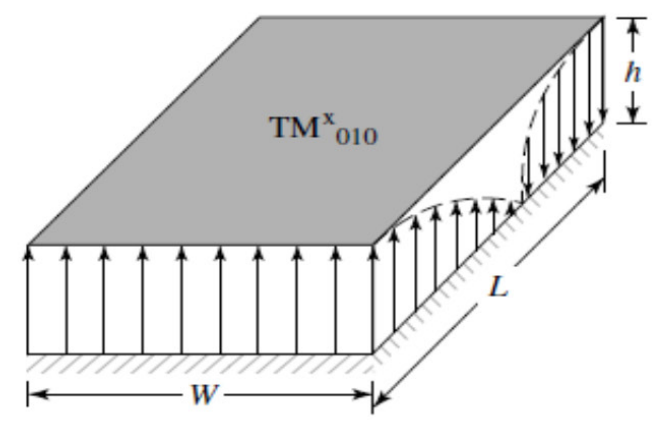

(a) $\mathrm{TM}_{010}^{\mathrm{x}}$

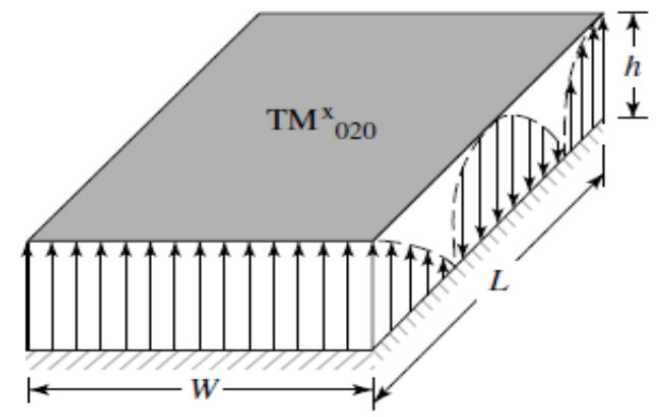

(c) $\mathrm{TM}_{020}^{\mathrm{x}}$

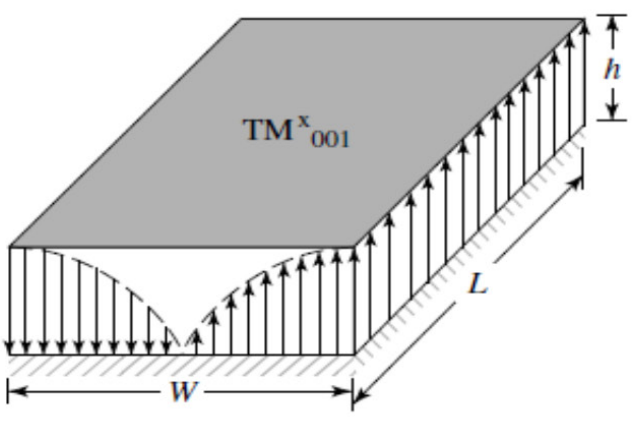

(b) $\mathrm{TM}^{\mathrm{x}}{ }_{001}$

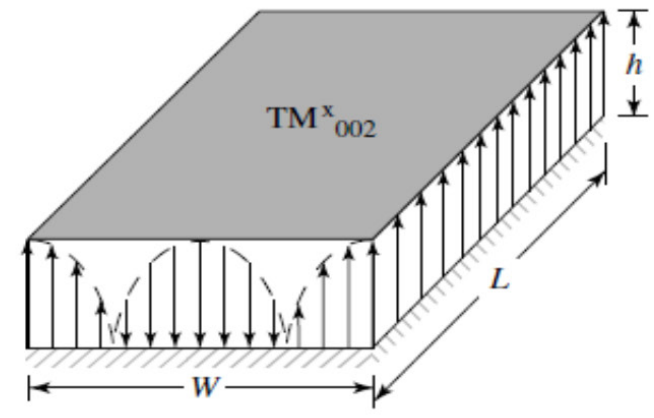

(d) $\mathrm{TM}^{\mathrm{x}}{ }_{002}$

Figure 2.10: Field configurations (modes) for rectangular microstrip patch. 


\section{Chapter 3: Background}

\subsection{Scattering Parameter and Reflection coefficient}

Scattering parameter is abbreviated as S-parameter and S-parameters are useful in representing circuit characteristics. The complete behavior of the circuit can be expressed through these S-parameters. Voltage and current wave can be considered as travelling wave that propagates in both direction. When propagating wave strikes on port 1 , some of the incident wave is reflected back from port 1 whereas rest of the wave is transmitted from that port. Number of S-parameters depends on the number of ports, for 2-port network, there are four S-parameters: $\mathrm{S}_{11}, \mathrm{~S}_{12}, \mathrm{~S}_{21}$ and $\mathrm{S}_{22}$. $\mathrm{S}_{11}$ and $\mathrm{S}_{22}$ are the reflection coefficients as reflection occurs from the same single port whereas $S_{12}$, and $S_{21}$ are transmission coefficients as transmission takes place between two ports. Amplitude and phase of the transmitted and reflected signal differ from the amplitude and phase of the incident signal. Generally transmitted and reflected signal have the same frequency as with the frequency of the incident signal. Scattering parameter $\mathrm{S}_{\mathrm{xy}}$ refers to the reflected (transmitted) signal from port $\mathrm{x}$ for the excitation signal at port $\mathrm{y}$ where $\mathrm{x}, \mathrm{y}$ are 1 and 2 for 2 port network. $\mathrm{S}_{\mathrm{xy}}$ is the ratio of the two signals, the reflected (transmitted) signal from port $\mathrm{x}$ over the excitation signal at port $y$. 


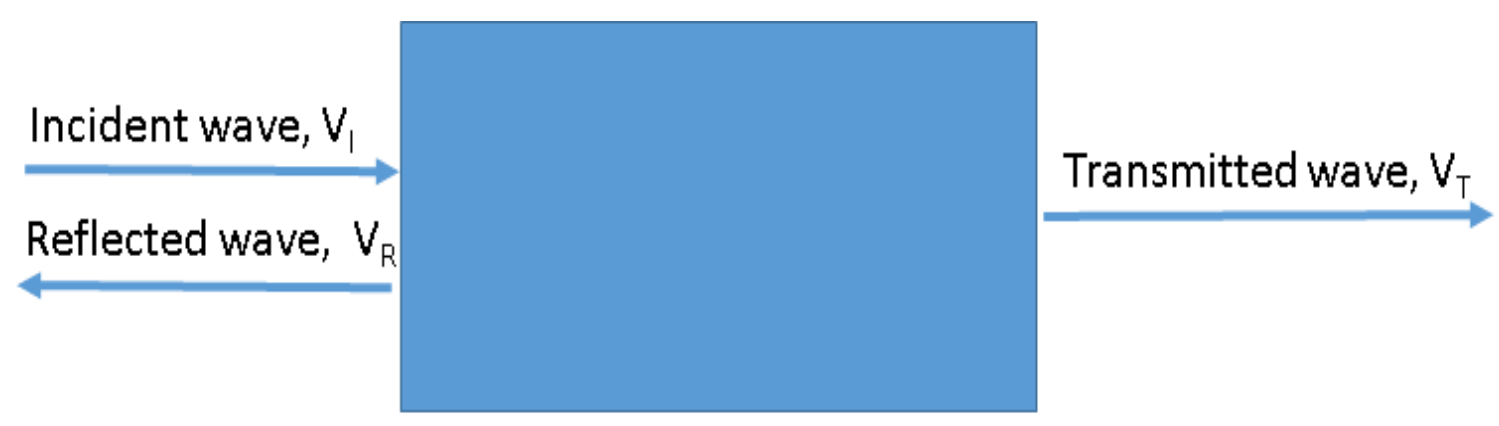

Port $1 \quad$ Port 2

Figure 3.1: Different waves along with the black box representation

$$
\begin{gathered}
S_{11}=\text { the reflected signal from port } 1 \text { over the excitation signal at port } 1=\frac{V_{R}}{V_{I}} \\
S_{21}=\text { the transmitted signal from port } 2 \text { over the excitation signal at port } 1=\frac{V_{T}}{V_{I}}
\end{gathered}
$$

Now if we consider incident signal is at $V_{I}$ is at port 2, then $V_{R}$ will be the transmitted signal whereas $\mathrm{V}_{\mathrm{T}}$ will be the reflected signal.

$$
\begin{gathered}
S_{12}=\text { the transmitted signal from port } 1 \text { over the excitation signal at port } 2=\frac{V_{R}}{V_{I}} \\
S_{22}=\text { the reflected signal from port } 2 \text { over the excitation signal at port } 2=\frac{V_{T}}{V_{I}}
\end{gathered}
$$

S-parameters can be interpreted physically as follows- $S_{11}$ is the input reflection coefficient with the output is matched to the load characteristic impedance $Z_{0}, S_{21}$ is the forward transmission gain or loss, $\mathrm{S}_{12}$ is the reverse transmission or isolation and $\mathrm{S}_{22}$ is the output reflection coefficient with the input matched to the load characteristic impedance $\mathrm{Z}_{0}$. S- 
parameters are complex, they both have magnitude and a phase but most often we use only their magnitude as they are the most important parameters to consider for network analysis. S-parameters depend on the network to analyze, different networks offer different values for S-parameters. S-parameters also depend on the operation frequency, if the frequency is changed the S-parameters will also be changed.

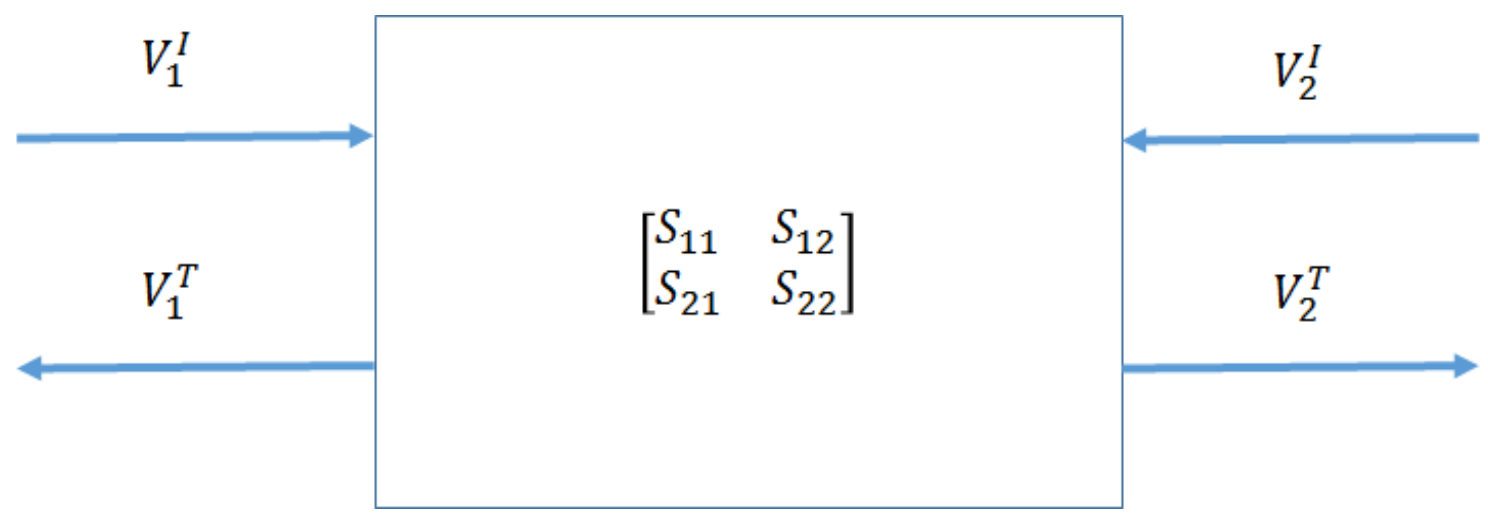

Figure 3.2: Incidence, Reflected and Transmitted voltages along with the Scattering parameters

The scattering parameters for the 2-port networks is related to the incident and transmitted (reflected) waves as follows:

$$
\begin{aligned}
& {\left[\begin{array}{l}
V_{1}^{T} \\
V_{2}^{T}
\end{array}\right]=\left[\begin{array}{ll}
S_{11} & S_{12} \\
S_{21} & S_{22}
\end{array}\right]\left[\begin{array}{l}
V_{1}^{I} \\
V_{2}^{I}
\end{array}\right]} \\
& V_{1}^{T}=S_{11} V_{1}^{I}+S_{12} V_{2}^{I} \\
& V_{2}^{T}=S_{21} V_{1}^{I}+S_{22} V_{2}^{I}
\end{aligned}
$$


For the short circuited load, output reflection coefficient $\Gamma_{\mathrm{L}}$ is -1 . Then

$$
\begin{gathered}
\Gamma_{L}=\frac{V_{2}^{T}}{V_{2}^{I}} \\
=>-1=\frac{V_{2}^{T}}{V_{2}^{I}} \\
=>\quad V_{2}^{I}=-V_{2}^{T}
\end{gathered}
$$

Now substituting this value into (3.1) and (3.2);

$$
\begin{aligned}
& V_{1}^{T}=S_{11} V_{1}^{I}-S_{12} V_{2}^{T} \\
& V_{2}^{T}=S_{21} V_{1}^{I}-S_{22} V_{2}^{T}
\end{aligned}
$$

After rearrangement of (3.4)

$$
\begin{gathered}
V_{2}^{T}+S_{22} V_{2}^{T}=S_{21} V_{1}^{I} \\
V_{2}^{T}=\frac{S_{21}}{1+S_{22}} V_{1}^{I}
\end{gathered}
$$

Substituting this value into (3.3)

$$
V_{1}^{T}=S_{11} V_{1}^{I}-S_{12} \frac{S_{21}}{1+S_{22}} V_{1}^{I}
$$

If we define input reflection coefficient as $\Gamma$ then from (3.5),

$$
\Gamma=\frac{V_{1}^{T}}{V_{1}^{I}}=S_{11}-S_{12} \frac{S_{21}}{1+S_{22}}
$$

As we can see from (3.6), in generally scattering parameter $S_{11}$ is not equal to the reflection coefficient of the network. If the reverse transmission or isolation is i.e. $\mathrm{S}_{12}$ is zero then $\Gamma$ Page $\mathbf{3 0}$ of $\mathbf{7 4}$ 
reduces to $S_{11}$. The reverse transmission or isolation is zero when load is matched to the characteristic impedance $\mathrm{Z}_{0}$ of the transmission line. Hence for a perfectly match network reflection coefficient of the network equals to the scattering parameter $\mathrm{S}_{11}$.

\subsection{Antenna Quality Factors}

The quality factor is a figure-of-merit that is represent the antenna losses [17].

$$
\frac{1}{Q_{t}}=\frac{1}{Q_{\text {rad }}}+\frac{1}{Q_{c}}+\frac{1}{Q_{d}}+\frac{1}{Q_{s w}}
$$

where

$Q_{t}=$ total quality factor

$Q_{\text {rad }}=$ quality factor due to radiation (space wave) losses $=\frac{2 \omega \epsilon_{r}}{h G_{t} / l} K$

$Q_{c}=$ quality factor due to conduction (ohmic) losses $=h \sqrt{\pi f \mu \sigma}$

$Q_{d}=$ quality factor due to dielectric losses $=\frac{1}{\tan \delta}=\frac{\varepsilon^{\prime}}{\varepsilon^{\prime \prime}}$

$Q_{s w}=$ quality factor due to surface waves

\subsection{Antenna Bandwidth}

The antenna bandwidth is characterized as the frequency range where the antenna obeys certain principles concerning some antenna characteristic and the bandwidth is 
centered at the resonance frequency of the antenna. The antenna characteristics such as efficiency, directivity, gain, radiation pattern, side lobe level, beam width, input impedance, and polarization are within an acceptable value at that resonance frequency. For the broadband operation, bandwidth is normally expressed as the ratio of the upper operational frequency range over the lower operational frequency range. For instance 12:1 bandwidth corresponds that the upper frequency is 12 times higher than the lower frequency. Whereas for the narrowband operation, bandwidth is usually expressed as the percentage of the operational frequency difference (upper to lower) to the center frequency of the bandwidth. For instance $8 \%$ bandwidth specifies that frequency difference between upper and lower band is $8 \%$ over to the center frequency. Bandwidth $(B W)$ is inversely proportional to the total quality factor, $Q_{t}[17]$

$$
\begin{aligned}
& B W=\frac{\Delta f}{f_{0}}=\frac{1}{Q_{t}} \\
& B W \sim \text { Volume }=\text { Length. Width . height } \\
& \sim \frac{1}{\sqrt{\epsilon_{r}}} \frac{1}{\sqrt{\epsilon_{r}}} \sqrt{\epsilon_{r}}=\frac{1}{\sqrt{\epsilon_{r}}}
\end{aligned}
$$

From above equation we can say that the bandwidth is increased as the permittivity of the dielectric constant is reduced and vice versa.

\subsection{Antenna Directivity}

The directivity of an antenna is the directional characteristic of an antenna. It measures how the antenna directs its maximum signal to a certain direction. The directivity can be 
measured as the ratio of the radiation intensity in a specific direction to the averaged radiation intensity over all directions [17]. The average antenna radiation intensity is a measure of the total power radiated per solid angle of the antenna. If the direction to which directivity is to be calculated is not provided, directivity should be measured in the direction of the maximum radiation. In more general, the directivity of a non-isotropic antenna is a measure to the ratio of its radiation intensity in a specific direction over the radiation intensity of an isotropic antenna. In Mathematical form, the directivity can be expressed as

$$
\begin{gathered}
D=\frac{U}{U_{0}}=\frac{4 \pi U}{P_{\text {rad }}} \\
D_{\text {max }}=D_{0}=\frac{U_{\mid \max }}{U_{0}}=\frac{U_{\text {max }}}{U_{0}}=\frac{4 \pi U}{P_{\text {rad }}}
\end{gathered}
$$

where

$\mathrm{D}=$ directivity (dimensionless)

$\mathrm{D}_{0}=$ maximum directivity (dimensionless)

$\mathrm{U}=$ radiation intensity $(\mathrm{W} / \mathrm{unit}$ solid angle)

$\mathrm{U}_{\max }=$ maximum radiation intensity (W/unit solid angle)

$\mathrm{U}_{0}=$ radiation intensity of isotropic source (W/unit solid angle)

$\mathrm{P}_{\mathrm{rad}}=$ total radiated power $(\mathrm{W})$ 


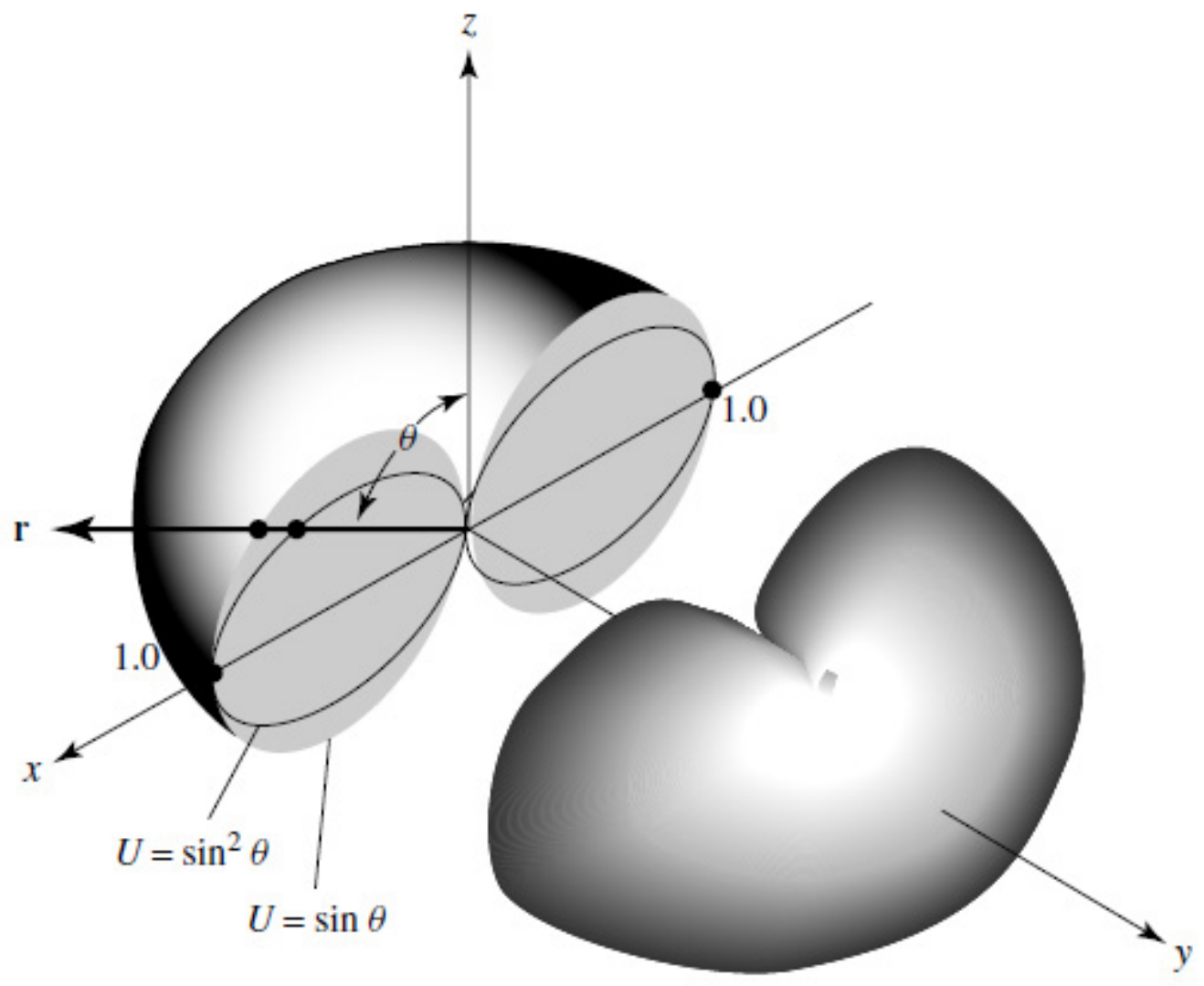

Figure 3.3: Directivity of the Antenna, directional in azimuth $x-y$ plane whereas nondirectional in elevation $\mathrm{x}-\mathrm{z}$ plane

In Figure 3.3 we have plotted the relative radiation intensities $U=A_{0} \sin \theta$ and $U=A_{0} \sin ^{2} \theta$ where $A_{0}$ is set equal to unity. Both of these patterns are omnidirectional in elevation plane and later pattern is more directional (narrower) as compared to the previous pattern, hence later pattern has the higher directivity. 


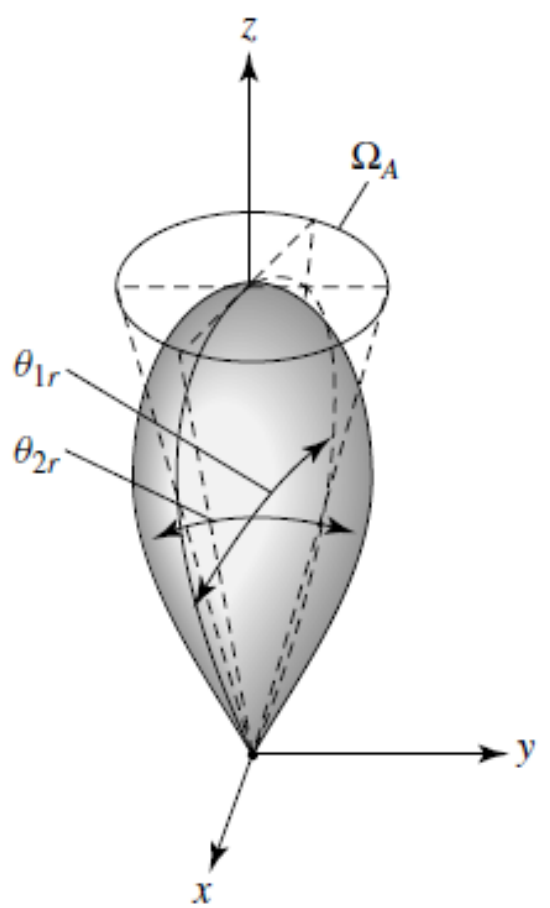

(a) Nonsymmetrical pattern

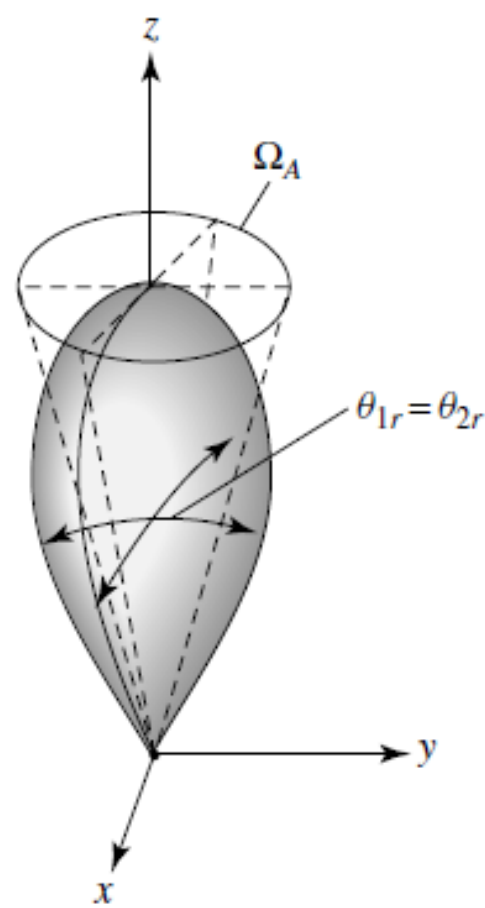

(b) Symmetrical pattern

Figure 3.4: Antenna directivity calculation from the antenna beam solid angle

The directivity of an antenna can also be measured from the beam solid angle $\Omega_{\mathrm{A}}$, the angle through which all the power is radiated such as

$$
\begin{aligned}
D_{0} & =\frac{4 \pi}{\Omega_{A}} \cong \frac{4 \pi}{\theta_{1 r} \theta_{2 r}} \\
\Omega_{A} & =\theta_{1 r} \theta_{2 r}
\end{aligned}
$$

where

$$
\begin{aligned}
& \theta_{1 r}=\text { half-power beamwidth in a specific plane (rad) and } \\
& \theta_{2 r}=\text { half-power beam width in a orthogonal plane to that specific plane (rad) }
\end{aligned}
$$

The directivity of an antenna is a dimensionless characteristic and usually express in decibel (dB). 


$$
\begin{aligned}
& D(d B)=10 \log _{10}[D(\text { dimensionless })] \\
& D_{0}(d B)=10 \log _{10}[D(\text { dimensionless })]
\end{aligned}
$$

\subsection{Antenna Efficiency}

Antenna efficiency is a key figure of merit of an antenna and it measures how efficiently it radiates power in certain direction. There are different types of efficiencies related to the antenna. Total antenna efficiency $\epsilon_{0}$ considers all sorts of losses associated with the antenna including input mismatch loss or reflection loss, conduction loss, dielectric loss etc. [17]. 

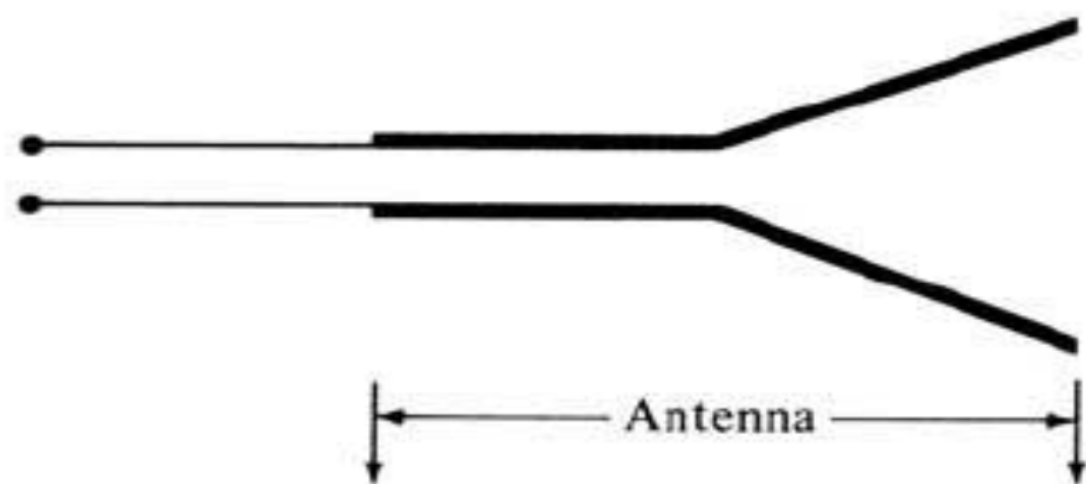

Input terminals (gain reference)

\section{Output}

terminals

(directivity reference)

(a) Antenna reference terminals

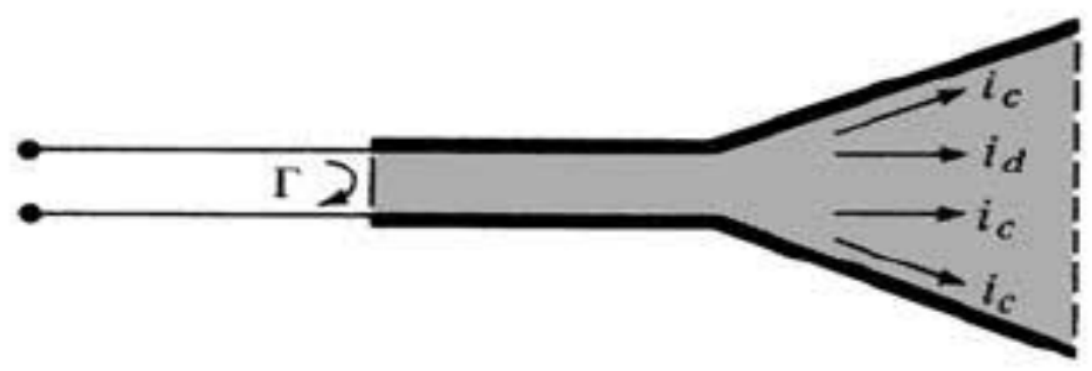

(b) Reflection, conduction, and dielectric losses

Figure 3.5: Antenna reference terminals along with its associated losses

$$
\epsilon_{0}=\epsilon_{c} \epsilon_{d} \epsilon_{r}
$$

where

$$
\begin{aligned}
& \epsilon_{0}=\text { total efficiency (dimensionless) } \\
& \epsilon_{c}=\text { conduction efficiency (dimensionless) } \\
& \epsilon_{d}=\text { dielectric efficiency (dimensionless) }
\end{aligned}
$$


$\epsilon_{r}=$ reflection (mismatch) efficiency $=\left(1-|\Gamma|^{2}\right)($ dimensionless $)$

$\Gamma=$ voltage reflection coefficient at the input terminals of the antenna

$$
\Gamma=\frac{Z_{\text {in }}-Z_{0}}{Z_{\text {in }}+Z_{0}}
$$

where

$Z_{\text {in }}=$ antenna input impedance,

$Z_{0}=$ characteristic impedance of the transmission line]

$\mathrm{VSWR}=$ voltage standing wave ratio $=\frac{1+|\Gamma|}{1-|\Gamma|}$

$$
\epsilon_{0}=\epsilon_{c} \epsilon_{d} \epsilon_{r}=\epsilon_{c d} \epsilon_{r}=\epsilon_{c d}\left(1-|\Gamma|^{2}\right)
$$

where $\epsilon_{c} \epsilon_{d}=\epsilon_{c d}=$ antenna radiation efficiency, the gain and the directivity of the antenna is calculated through this antenna radiation efficiency.

The efficiency of the antennas can be calculated through their quality factors such as

$$
\epsilon_{c d}=\frac{Q_{t}}{Q_{r a d}}
$$

Again from bandwidth

$$
Q_{t} \sim \sqrt{\epsilon_{r}}
$$

And from quality factor due to radiation in space

$$
\begin{aligned}
& Q_{\text {rad }} \sim \epsilon_{r} \\
& \epsilon_{c d} \sim \frac{\sqrt{\epsilon_{r}}}{\epsilon_{r}}=\frac{1}{\sqrt{\epsilon_{r}}}
\end{aligned}
$$


From above equation we can deduce that the efficiency is increased as the permittivity of the dielectric constant is reduced and vice versa.

\subsection{Antenna Gain}

Another important antenna figure of merit is the antenna gain that measure its performance. Antenna gain is directly related to its directivity and its efficiency. Gain of an antenna in a specific direction is defined as a measure of the ratio of the intensity in a given direction to the radiation intensity of an isotropic antenna. The radiation intensity of an isotropic antenna is equal to the power accepted (input) by the antenna divided by $4 \pi$ [17].

$$
\text { Gain, } G=4 \pi \frac{\text { Radition intensity }}{\text { Total accepted (input)power }}=4 \pi \frac{U}{P_{\text {in }}}(\text { dimensionless })
$$

Again radiation efficiency, $\epsilon_{c d}$ is equal to the ratio of the radiated power $P_{r a d}$ over the input power $P_{\text {in }}$ such as

$$
\epsilon_{c d}=\frac{P_{r a d}}{P_{\text {in }}}
$$

Substituting $P_{\text {in }}$ in eq. (3.17), 


$$
\text { Gain, } G=\epsilon_{c d}\left[4 \pi \frac{U}{P_{\text {rad }}}\right]
$$

But from eq. (3.10), the directivity, $D$ of the antenna can be expressed as

$$
D=4 \pi \frac{U}{P_{r a d}}
$$

Substituting eq. (3.10) into eq. (3.19),

$$
G=\epsilon_{c d} D
$$

Maximum gain of the antenna is directly related its maximum directivity,

$$
G_{0}=G_{\max }=\epsilon_{c d} D_{\max }=\epsilon_{c d} D_{0}
$$

This antenna gain refers to the IEEE gain as this gain doesn't include reflection losses or mismatch losses and polarization losses whereas absolute gain, also called as realized gain does include reflection losses or mismatch losses. In mathematical form, absolute gain or realized gain $G_{a b s}$ can be expressed as

$$
G_{a b s}=\epsilon_{r} G=\epsilon_{r} \epsilon_{c d} D=\epsilon_{0} D
$$

As with the antenna directivity $D$, both gain and absolute gain can be expressed as in decibel,

$$
\begin{gathered}
G(d B)=10 \log _{10}[G(\text { dimensionless })] \\
G_{0}(d B)=10 \log _{10}[G(\text { dimensionless })]
\end{gathered}
$$




\subsection{Specific Absorption Rate (SAR)}

The cell phone antenna radiates power in its surrounding space and its temperature increases with the time of operation. Due to this radiation of electromagnetic wave in biological tissues, human tissues are severely affected by the electromagnetic radiation. All these limit the cell operation and specific absorption rate (SAR), a safety figure of merit measurement controls the electromagnetic radiation in biological tissues for well-being operation of the cell phone.
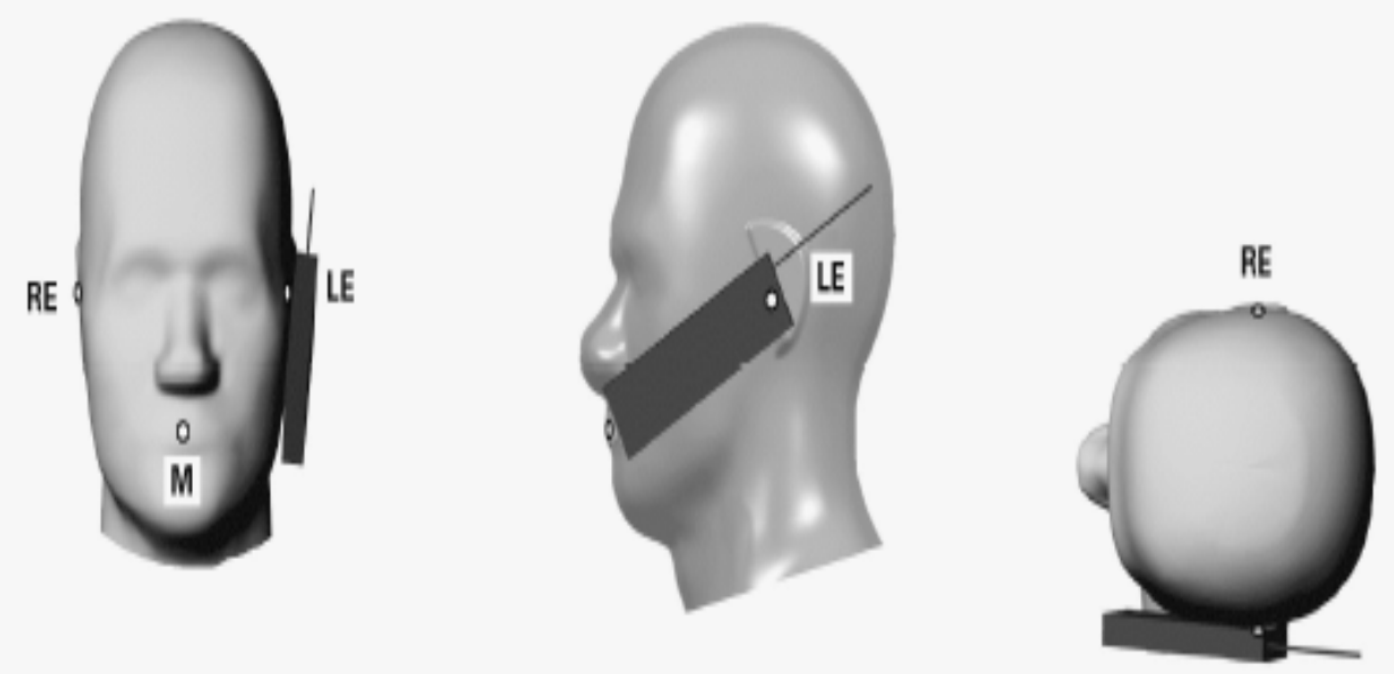

LE

Figure 3.6: Phone position 1 - cheek position. The reference points for the right ear (RE), left ear (LE), and mouth (M), which establish the Reference Plane for handset positioning, are indicated.

Specific absorption rate (SAR) is defined as the amount of power absorbed by the biological tissue of the human body and can be defined as $[18,19]$ 


$$
S A R=\frac{P}{\rho}=\frac{\sigma E^{2}}{\rho}
$$

In eq. (3.23), $\mathrm{P}$ is the absorbed power in Watts, $\mathrm{E}$ is the induced electric field in $\mathrm{V} / \mathrm{m}, \rho$ is the density of the mass in $\mathrm{kg} / \mathrm{m}^{3}$ and $\sigma$ is the conductivity in $\mathrm{S} / \mathrm{m}$ of the biological tissue.
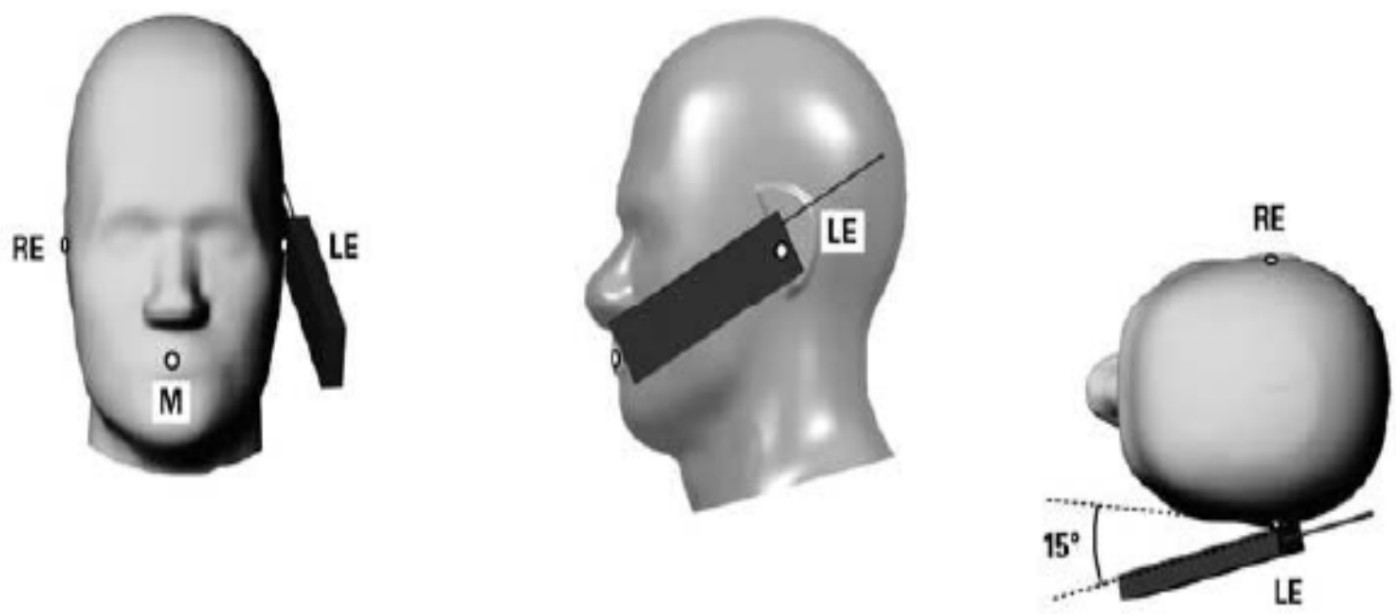

Figure 3.7: Phone position 2-tilt position. The reference points for the right ear (RE), left ear (LE), and mouth (M), which define the Reference Plane for handset positioning, are indicated.

Usually SAR is averaged over a finite mass $(10 \mathrm{~g}, 1 \mathrm{~g})$, sometimes in finite volume also. There are two standards to calculate SAR over the averaged mass: $1.6 \mathrm{~W} / \mathrm{kg}$ for $1.0 \mathrm{~g}$ biological tissues for USA (FCC), Australia (ACA) and $2 \mathrm{~W} / \mathrm{kg}$ for $10 \mathrm{~g}$ biological tissues for Europe (ICNIRP) $[19,20]$. SAR is usually calculated with the phantom head model composed of a liquid that resembles human head tissue. A detailed SAR measurement procedures and techniques with phantom head model is described in IEEE Std. 1528-2013 [21]. 


\section{Chapter 4: Proposed Antenna Design Technique}

NASA research fellow Meador et al. [22] explored different types of polyimide aerogels with low mass density, low thermal conductivity and higher durability. In addition to low mass and thermal conductivity, they investigated polyimide aerogel with a very low dielectric constant. They found that the dielectric constant of material is linearly proportional to its mass density. They have investigated a series of polyimide aerogels using Triaminophenoxybenzene (TAB), Dimethylbenzidine (DMBZ), Benzophenone tetracarboxylic dianhydride (BTDA) and Biphenyl tetracarboxylic dianydride (BPDA). They have reported a polyimide aerogel with a low dielectric constant of 1.249 and loss tangent of $1.54 \times 10^{-3}$ with a mass density of $131 \mathrm{~kg} / \mathrm{m}^{3}$ [22].

Figure 4.1 shows the proposed planar monopole antenna with polyimide aerogel substrate having low dielectric constant of 1.249 and loss tangent of $1.54 \times 10^{-3}$. A twosided copper coated polyimide aerogel with a surface area of $130 \times 40 \mathrm{~mm}^{2}$ and of $0.8 \mathrm{~mm}$ thickness is proposed as the cell phone circuit board. On one side of this circuit board, a

ground plane of size $40 \times 100 \mathrm{~mm}^{2}$ is etched at the bottom while a planar radiating plate of size $22 \times 40 \mathrm{~mm}^{2}$ is printed at the top of the circuit board. On the other side of the substrate, a simple slotted capacitive coupling strip of dimension $12.5 \times 9 \mathrm{~mm}^{2}$ is printed with a slot dimension of $8.9 \times 7.2 \mathrm{~mm}^{2}$. The slotted capacitive coupling strip is excited through a $50 \Omega$ microstrip feed line along with a microstrip printed between the feed gap. The planar radiating plate is short circuited to the system circuit board ground plate through a meandered wire. A uniform $0.256 \mathrm{~mm}$ width meandering microstrip of length $28 \mathrm{~mm}$ is 
printed to short circuit the radiating plate to the ground plane. The entire circuit board and its associated components are enclosed in a plastic casing with relative permittivity 3.0 and conductivity $0.02 \mathrm{~S} / \mathrm{m}$ and the total overall thickness of the mobile phone corresponds to $9.8 \mathrm{~mm}$.

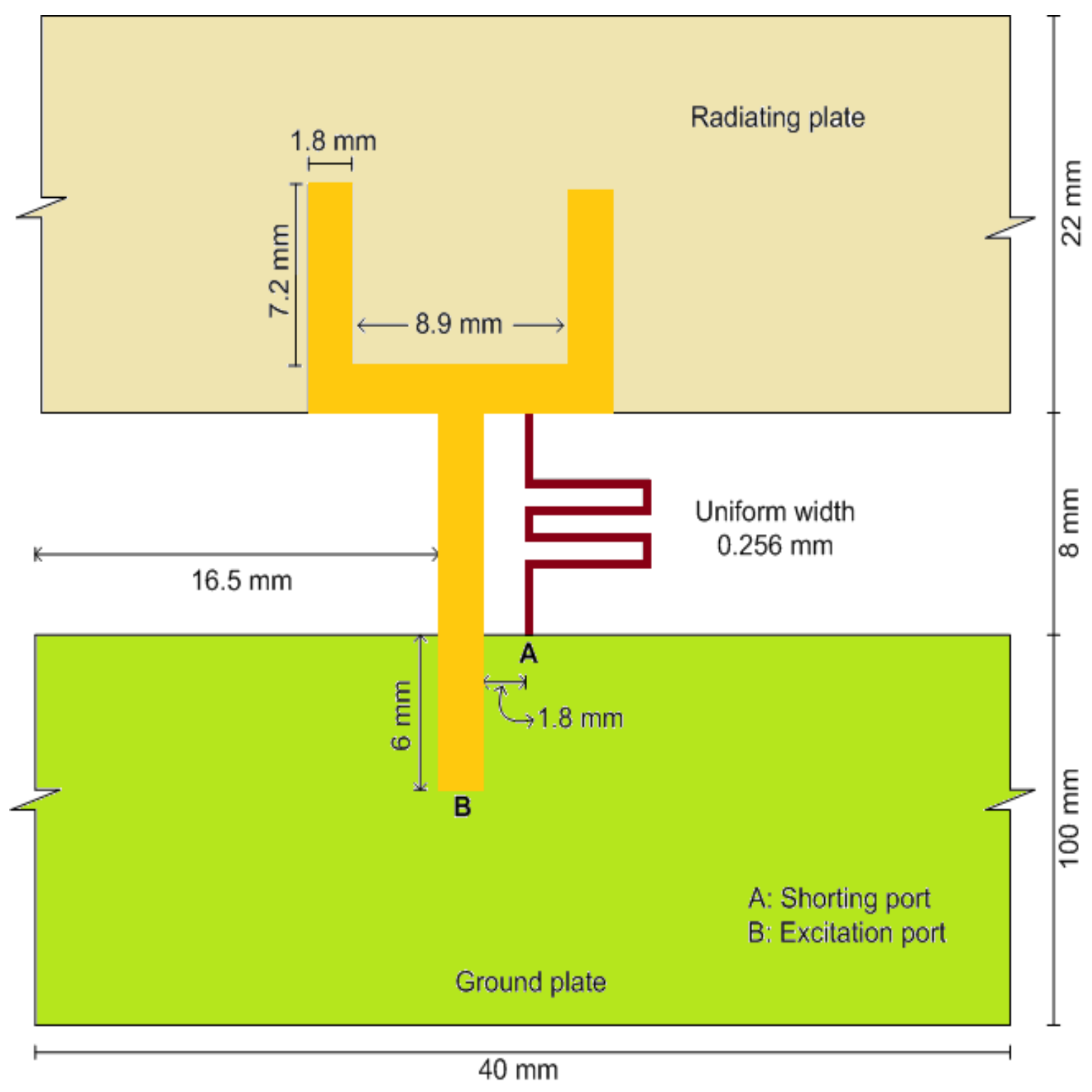

Figure 4.1 Geometry of the proposed planar monopole polyimide aerogel antenna 


\section{Chapter 5: Result and Analysis}

All calculations and analysis were performed through the commercially available fullwave simulation software CST MWS and the time domain transient solver is used for our simulation [23].

\subsection{Surface Current Distribution}

Surface current is generated both in meandered inductive shorting strip as well as in coupled capacitive strip of this proposed antenna. This surface current in turn produces resonance characteristics, resonance frequency is measured though the resonating length of the antenna. Resonance frequency is inversely proportional to the resonating length [24]. Effective relative permittivity,

$$
\varepsilon_{\text {reff }}=\frac{\varepsilon_{r}+1}{2}
$$

Effective wave length,

$$
\lambda_{e f f}=\frac{8 *(\text { Length of the resonating strip })}{\varepsilon_{\text {reff }}}
$$

Resonance frequency,

$$
f_{r}=\frac{c}{\lambda_{e f f}}
$$

Here $\mathrm{c}$ is light speed in free space. 


\subsubsection{Surface Current at Lower Band}

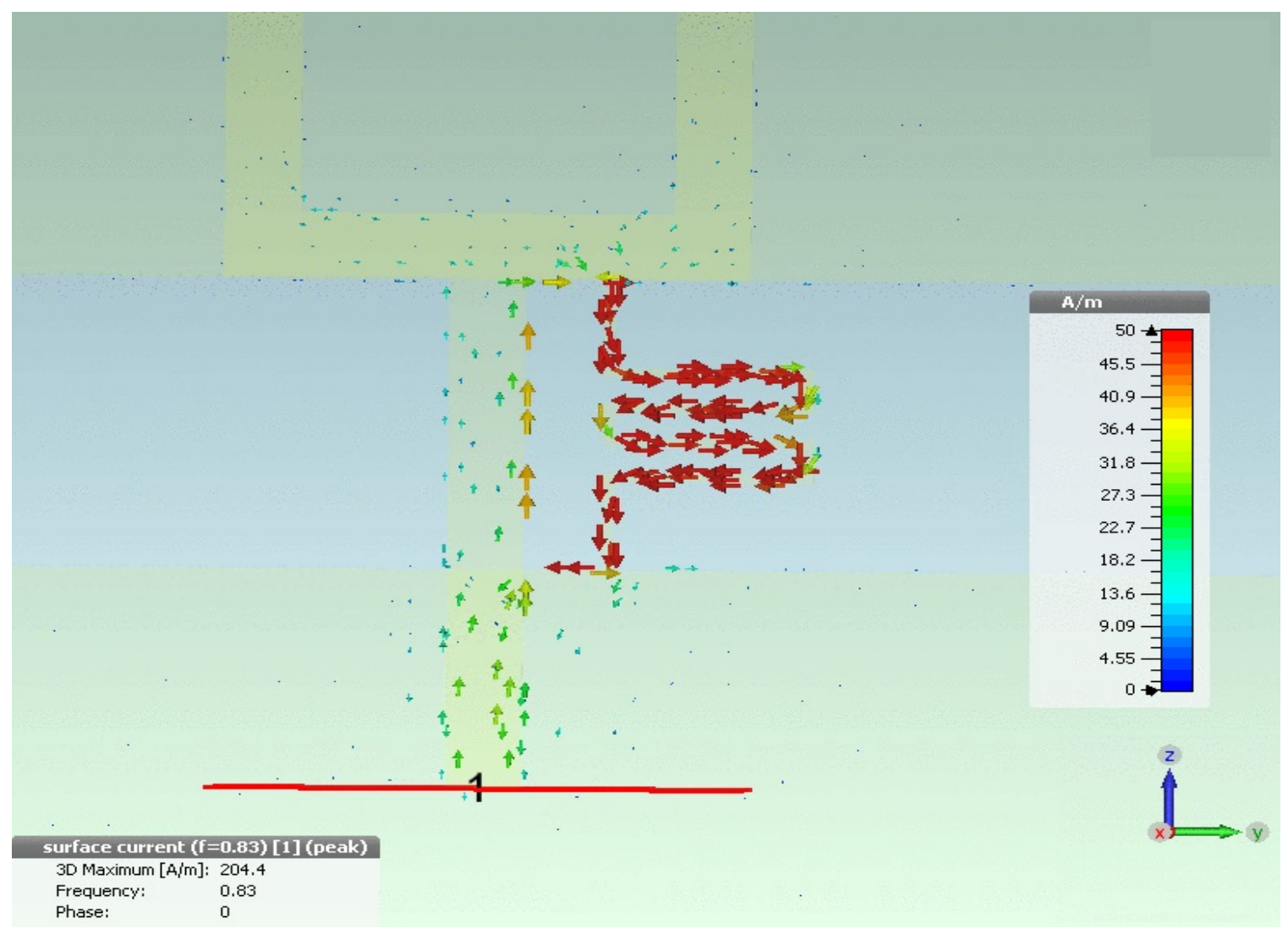

Figure 5.1: Surface current distribution due to inductive shorting at $830 \mathrm{MHz}$

Figure 5.1 shows the surface current distribution of our proposed antenna for the lower band at $830 \mathrm{MHz}$. Strong surface current is induced in meander wire connected between radiating plate and system ground plate. Measured maximum surface current on this wire is approximately $204 \mathrm{~A} / \mathrm{m}$. This current generates low frequency resonance and widen the lower operational frequency band from $695 \mathrm{MHz}$ up to approximately $1500 \mathrm{MHz}$. Radiating plate has a length of $22 \mathrm{~mm}$ while meandered inductive shorting strip has a length of $28 \mathrm{~mm}$. Radiating plate along with meandered wire provide a resonating length of $22+$ 
$28=50 \mathrm{~mm}$. Relative permittivity $\varepsilon_{r}$ of the polyimide aerogel is 1.249 . With this resonating length of $50 \mathrm{~mm}$, theoretical resonance frequency can be approximated at $843 \mathrm{MHz}$ which is close enough to the center frequency of the lower operational band.

\subsubsection{Surface current at upper Band}

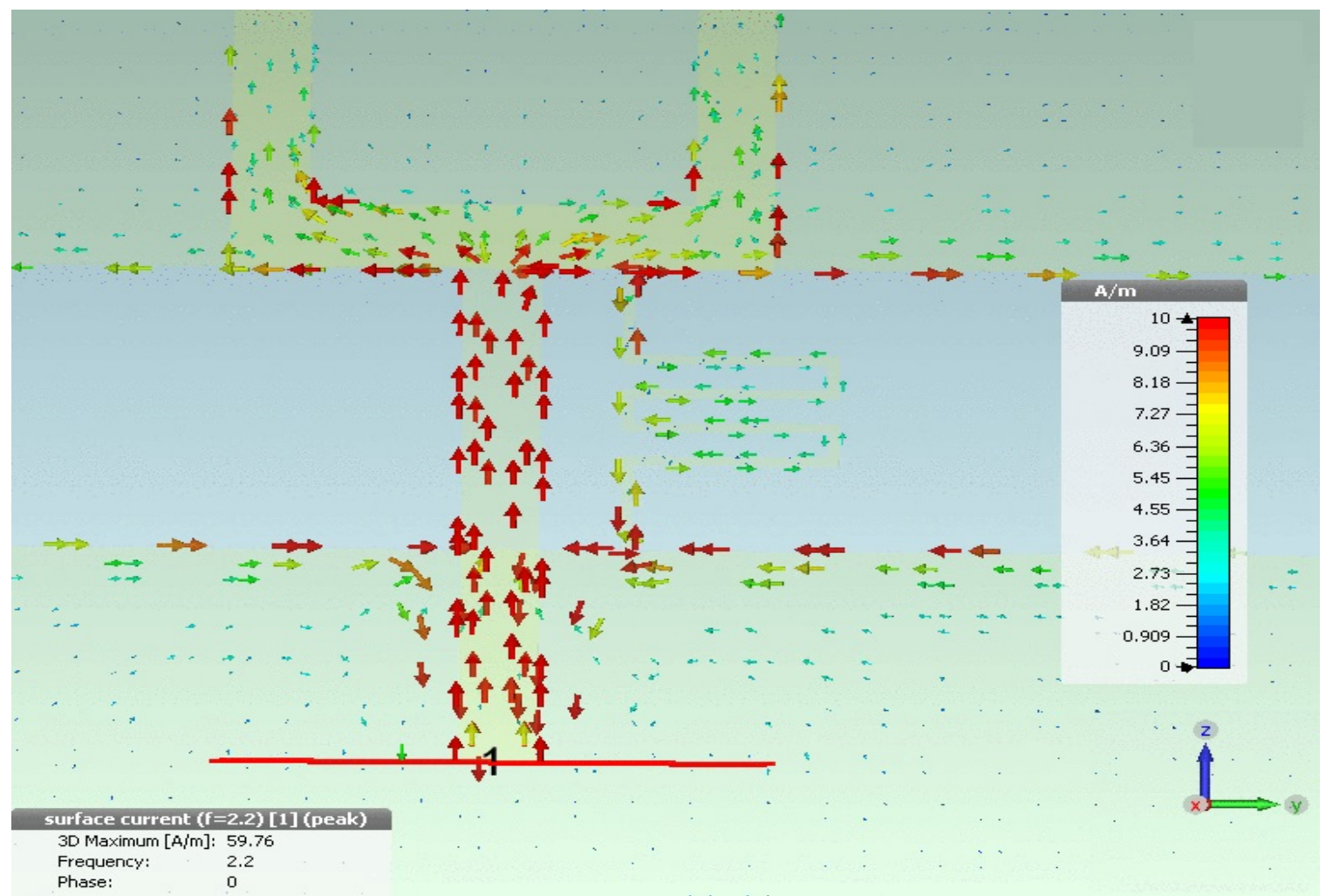

Figure 5.2: Surface current distribution due to inductive shorting at $2200 \mathrm{MHz}$

Figure 5.2 shows the surface current distribution of the proposed antenna at 2200 $\mathrm{MHz}$, center frequency of the upper band. Tense surface current is induced in the capacitively coupled slotted strip printed opposite site of the radiating plate. Measured maximum surface current on this coupled slotted wire is approximately $60 \mathrm{~A} / \mathrm{m}$. This 
current generates high frequency resonance and widen the upper operational frequency band from approximately $1500 \mathrm{MHz}$ up to $2845 \mathrm{MHz}$. Slotted capacitive wire provides a resonating length of $12.5+7.2=19.7 \mathrm{~mm}$. With polyimide aerogel of relative permittivity $\varepsilon_{r}$ of 1.249 and resonating length of $19.7 \mathrm{~mm}$, theoretical resonance frequency can be approximated at $2140 \mathrm{MHz}$ which is close enough to the center frequency of the upper operational band.

\subsection{Voltage Standing Wave Ratio (VSWR) Measurement}

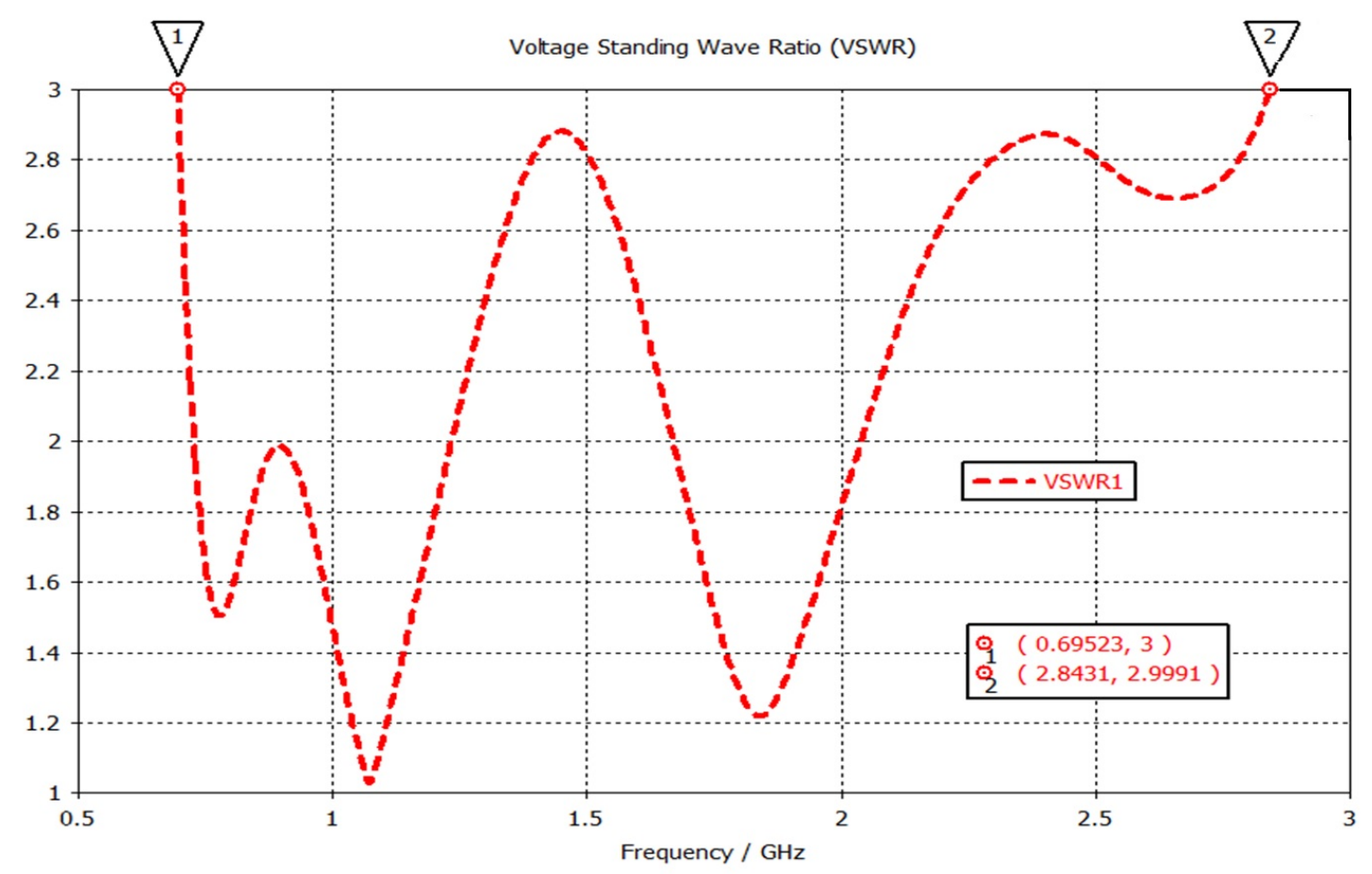

Figure 5.3: Simulated Voltage Standing wave ratio for our proposed antenna 
For the entire operational frequency range VSWR for the polyimide aerogel is within $\mathrm{VSWR}=3: 1$ limit.

\subsection{Return Loss Measurement}
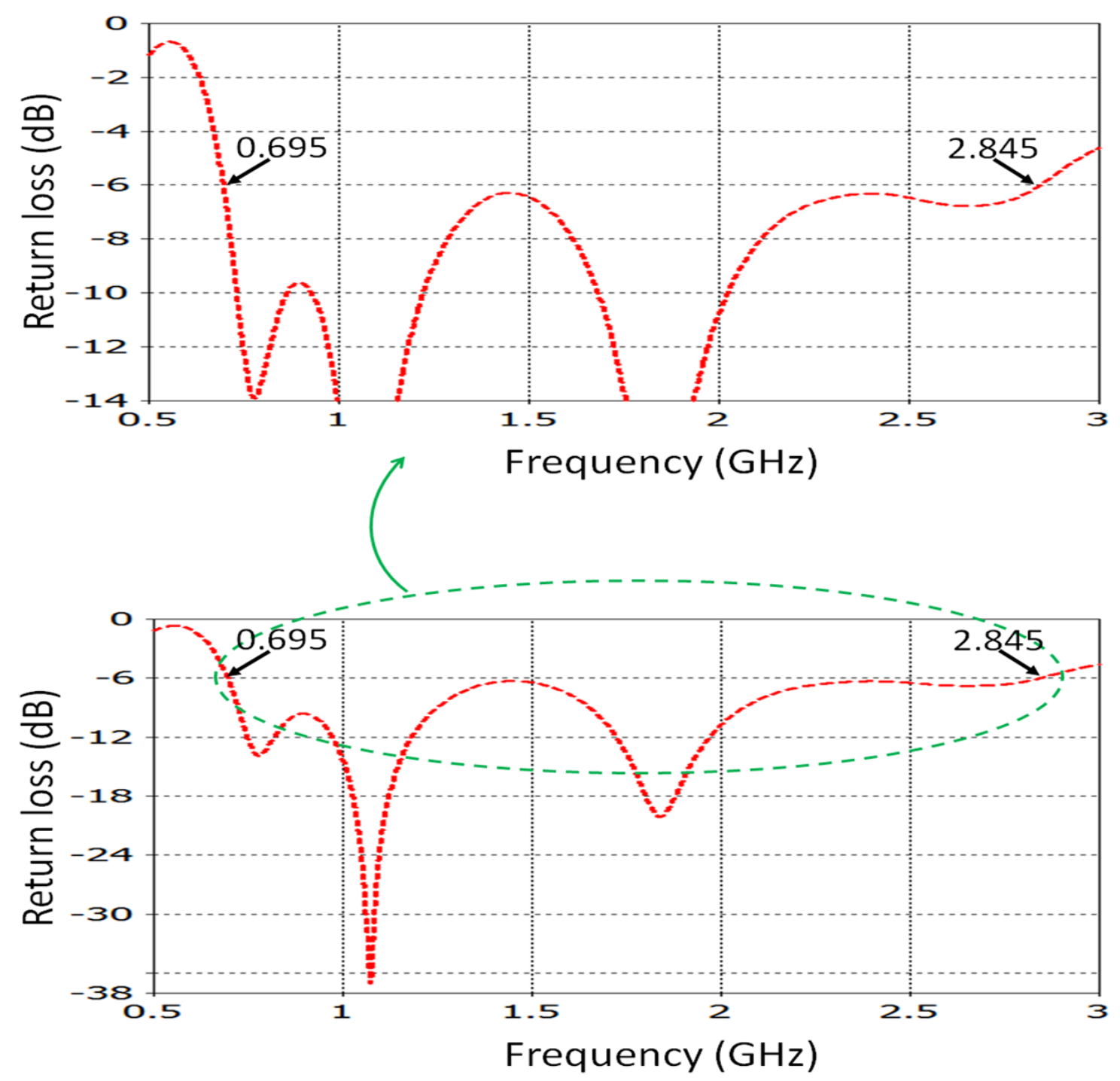

Figure 5.4: Return loss of the proposed polyimide aerogel antenna at 3:1 VSWR 
In Figure 5.4, an ultra-wide band of $2150 \mathrm{MHz}$ is presented with a 3:1 VSWR standard for cell phone operation. This wide band is obtained through 3 resonances for inductive shorting and capacitive coupling strips and those resonance frequencies are controlled through the dimension of these two strips.

\subsection{Impedance Matching}

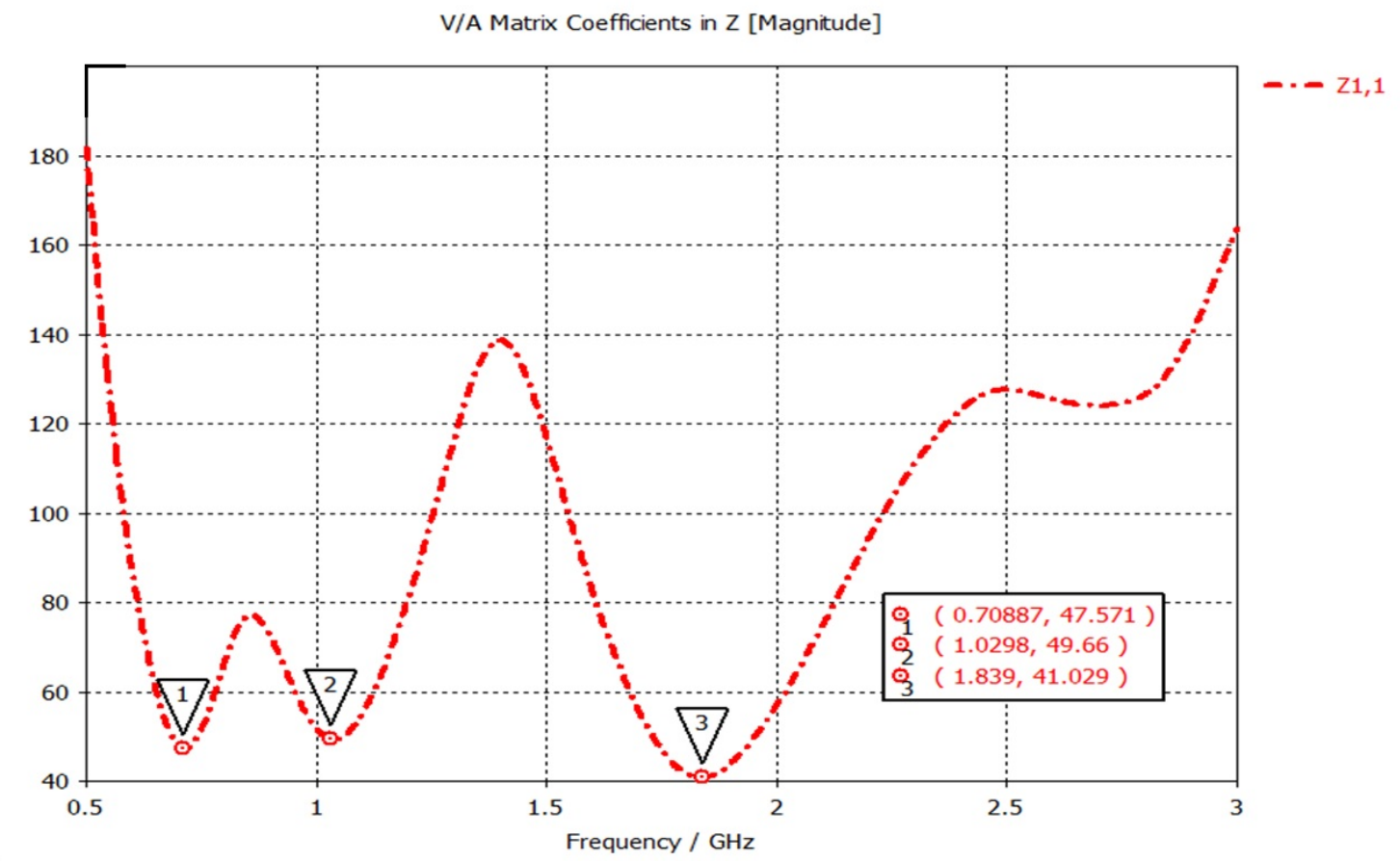

Figure 5.5: Plot of the input impedance of the antenna with impedance matching at resonance frequencies.

For our simulation wave port excitation is used with excitation impedance of $50 \Omega$. Better impedance match is observed at three resonance frequencies- $709 \mathrm{MHz}, 1.03 \mathrm{GHz}$ and $1.84 \mathrm{GHz}$. 


\subsection{Radiation Performance}

\subsubsection{Radiation Pattern}

Figure 5.6 and figure 5.7 show the radiation patterns at $830 \mathrm{MHz}$ and at $2200 \mathrm{MHz}$. $830 \mathrm{MHz}$ and $2200 \mathrm{MHz}$ are approximately the mid frequencies of the lower $(698-960$ $\mathrm{MHz}$ ) and upper (1710-2690 MHz) bands. For both $830 \mathrm{MHz}$ and $2200 \mathrm{MHz}$, omnidirectional radiation patterns are observed with maximum radiation in the azimuthal plane (x-y plane). Both for the lower band and upper band radiation patterns are directional in $x-z$ plane and $y-z$ plane whereas radiation patterns are non-directional in $x-y$ plane. Our radiation patterns are similar to the radiation patterns of the printed cell phone antennas $[25,26]$.

\subsubsection{Radiation Pattern at Lower Band}

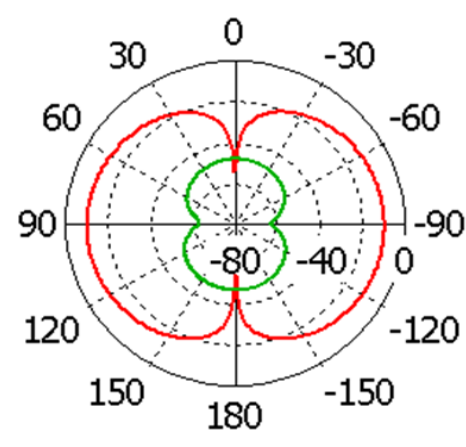

Theta / Degree vs. dBW/m2 $x-z$ plane

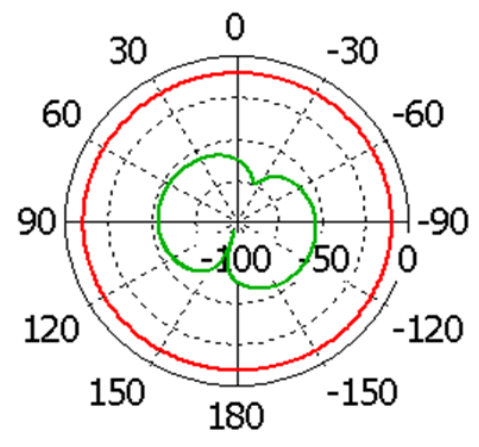

Phi / Degree vs. dBW/m2 $x-y$ plane $830 \mathrm{MHz}$

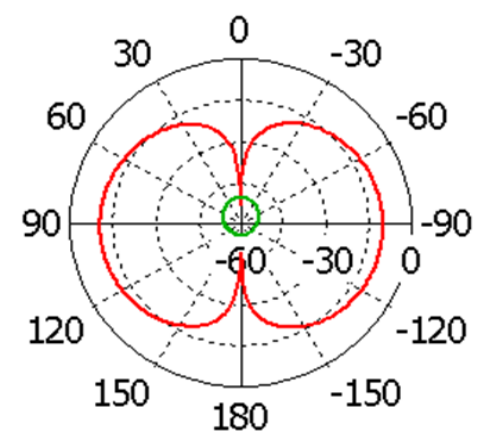

Theta / Degree vs. dBW/m2

$y-z$ plane

Figure 5.6: Radiation pattern of the proposed antenna at $830 \mathrm{MHz}$ (red - co-polar component and green - cross polar component) 


\subsubsection{Radiation Pattern at Upper Band}

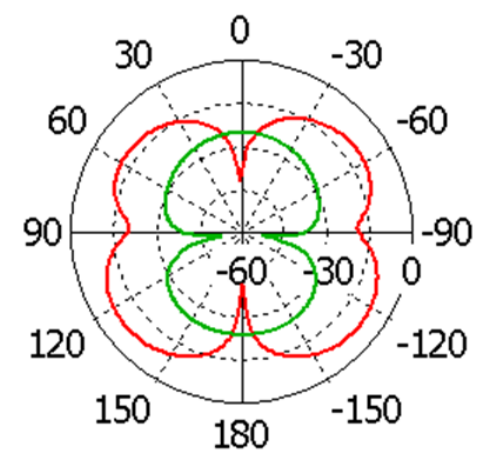

Theta / Degree vs. dBW/m2 $x$-z plane
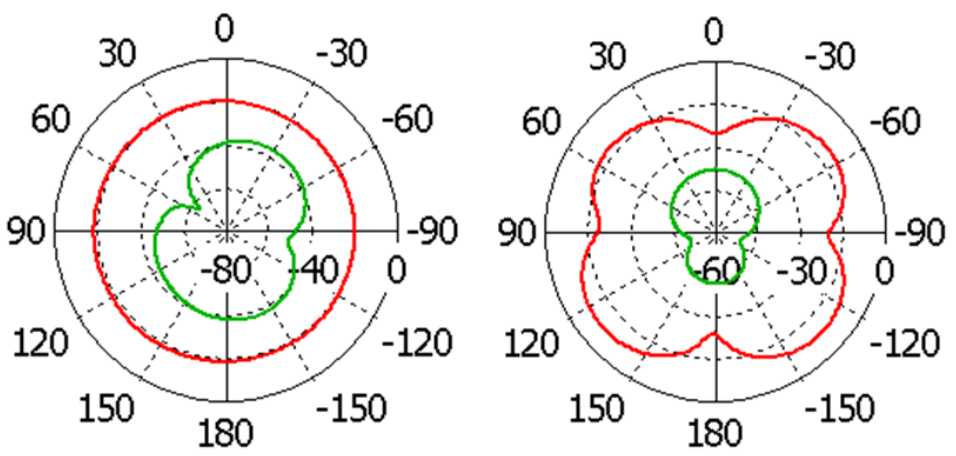

Phi / Degree vs. dBW/m2 $x-y$ plane $2200 \mathrm{MHz}$

Figure 5.7: Radiation pattern of the proposed antenna at $2200 \mathrm{MHz}$ (red - co-polar component and green - cross polar component) 


\subsubsection{Antenna Directivity}

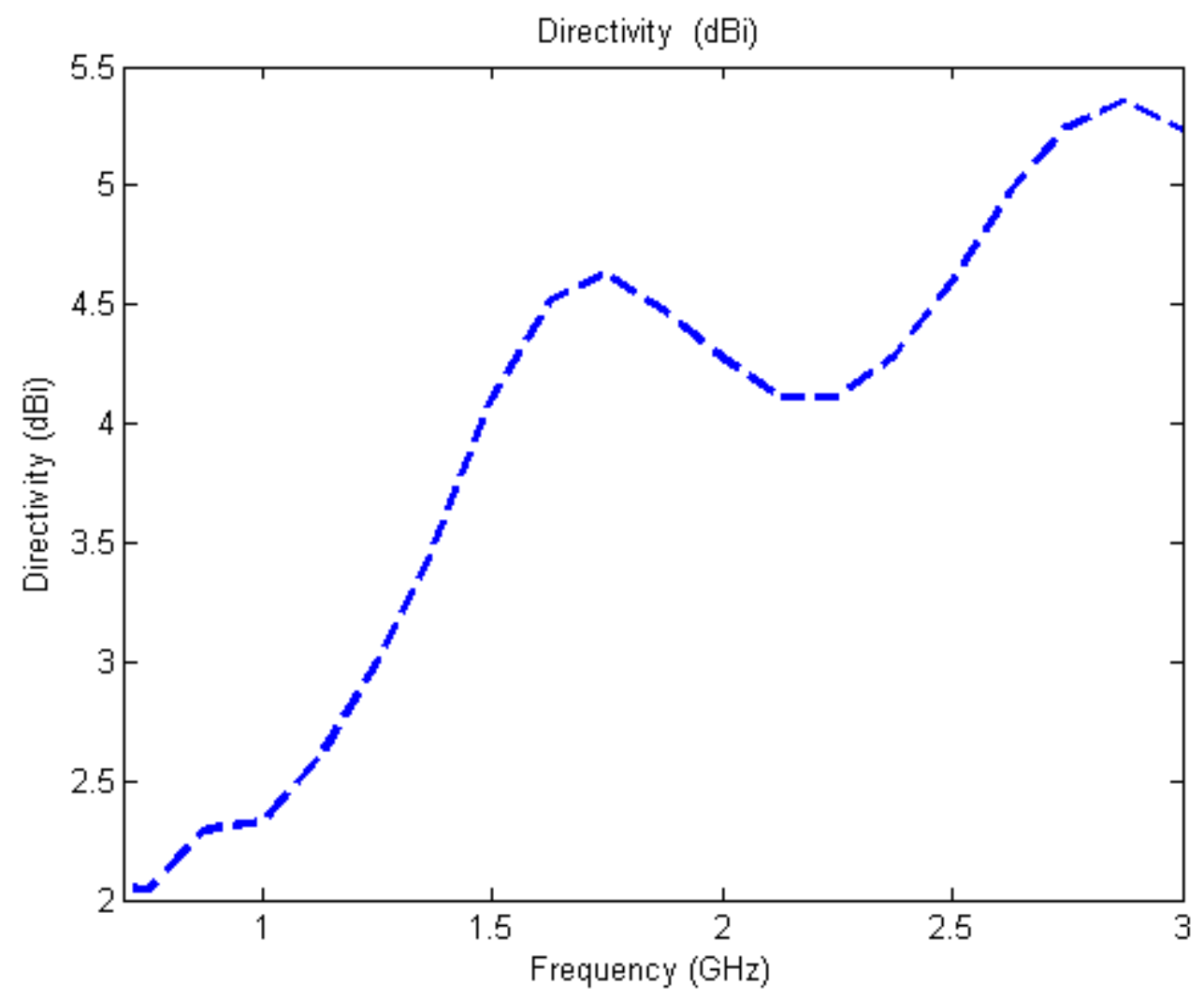

Figure 5.8: Plot of the directivity of the antenna while calculated w.r.t an isotropic antenna

The antenna directivity is calculated w.r.t an isotropic antenna. Maximum antenna directivity is measured as $3.43 \mathrm{dBi}$ and observed at $2.875 \mathrm{GHz}$. 


\subsubsection{Antenna Gain and Radiation efficiency}

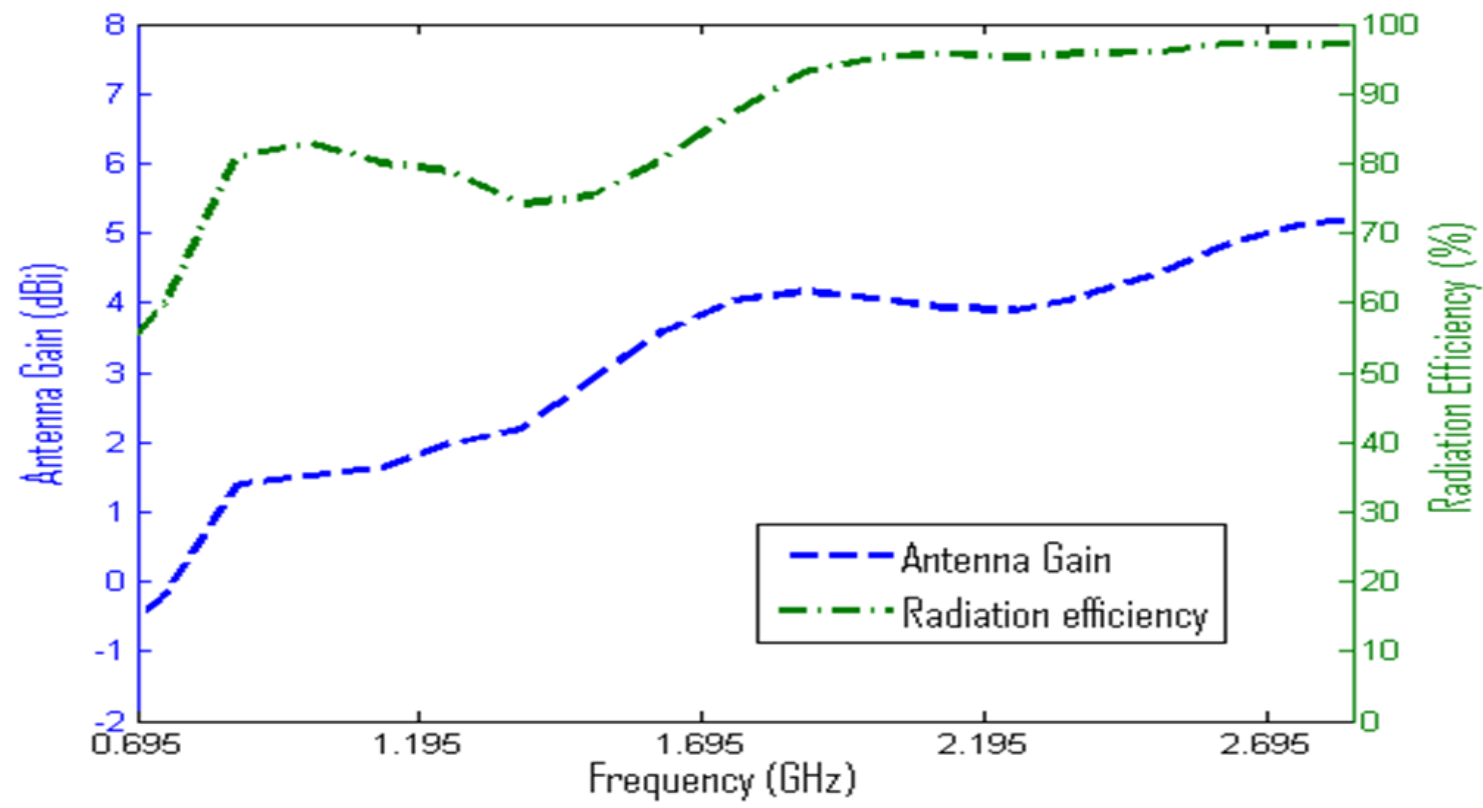

Figure 5.9: Gain and radiation efficiency of the proposed planar monopole polyimide aerogel antenna

Figure 5.9 shows the simulated antenna gain and radiation efficiency for the proposed antenna. For the lower WWAN operational frequency band $698-960 \mathrm{MHz}$, antenna gain ranges from $-1.45-1.39 \mathrm{dBi}$ while for the upper WWAN frequency band $1710-2690 \mathrm{MHz}$, the gain ranges from $3.8-4.95 \mathrm{dBi}$. Antenna radiation efficiency for the lower band is about to $60 \%$ to $81 \%$ and for the upper band the radiation efficiency is about to $85 \%$ to $97 \%$. In [25], maximum gain and radiation efficiency for the lower band are reported as $0.9 \mathrm{dBi}$ and $78 \%$ respectively, while for the upper band maximum gain and efficiency are reported as $3.8 \mathrm{dBi}$ and $92 \%$, respectively. Maximum gain and radiation efficiency of this proposed polyimide aerogel antenna for the lower band are $0.49 \mathrm{dBi}$ and 
$3 \%$ higher as compared to [25], respectively, while maximum gain and radiation efficiency for the upper band are $1.15 \mathrm{dBi}$ and 5\% higher, respectively.

\subsection{SAR Calculation}

\subsubsection{Measured SAR for finite weight biological tissues}

Table 5.1: Measured SAR at Check Position with the phantom head model

\begin{tabular}{|c|c|c|c|c|c|c|c|c|c|c|}
\hline $\begin{array}{c}\text { Frequency } \\
\text { (GHz) }\end{array}$ & 0.745 & 0.86 & 0.92 & 1.575 & 1.795 & 1.92 & 2.045 & 2.35 & 2.45 & 2.595 \\
\hline $\begin{array}{c}\text { Input Power } \\
\text { (mW/dBm) }\end{array}$ & 125 & 250 & 250 & 125 & 125 & 125 & 125 & 125 & 125 & 125 \\
\hline $\begin{array}{c}\text { SAR (1g, } \\
\text { W/Kg) }\end{array}$ & 0.43 & 0.78 & 0.77 & 1.51 & 1.10 & 0.88 & 0.89 & 0.95 & 1.07 & 1.07 \\
\hline $\begin{array}{c}\text { SAR(10g, } \\
\text { W/Kg) }\end{array}$ & 0.09 & 0.44 & 0.45 & 1.01 & 0.74 & 0.58 & 0.55 & 0.59 & 0.62 & 0.63 \\
\hline
\end{tabular}




\subsubsection{Effect of EM Radiation on human tissues}

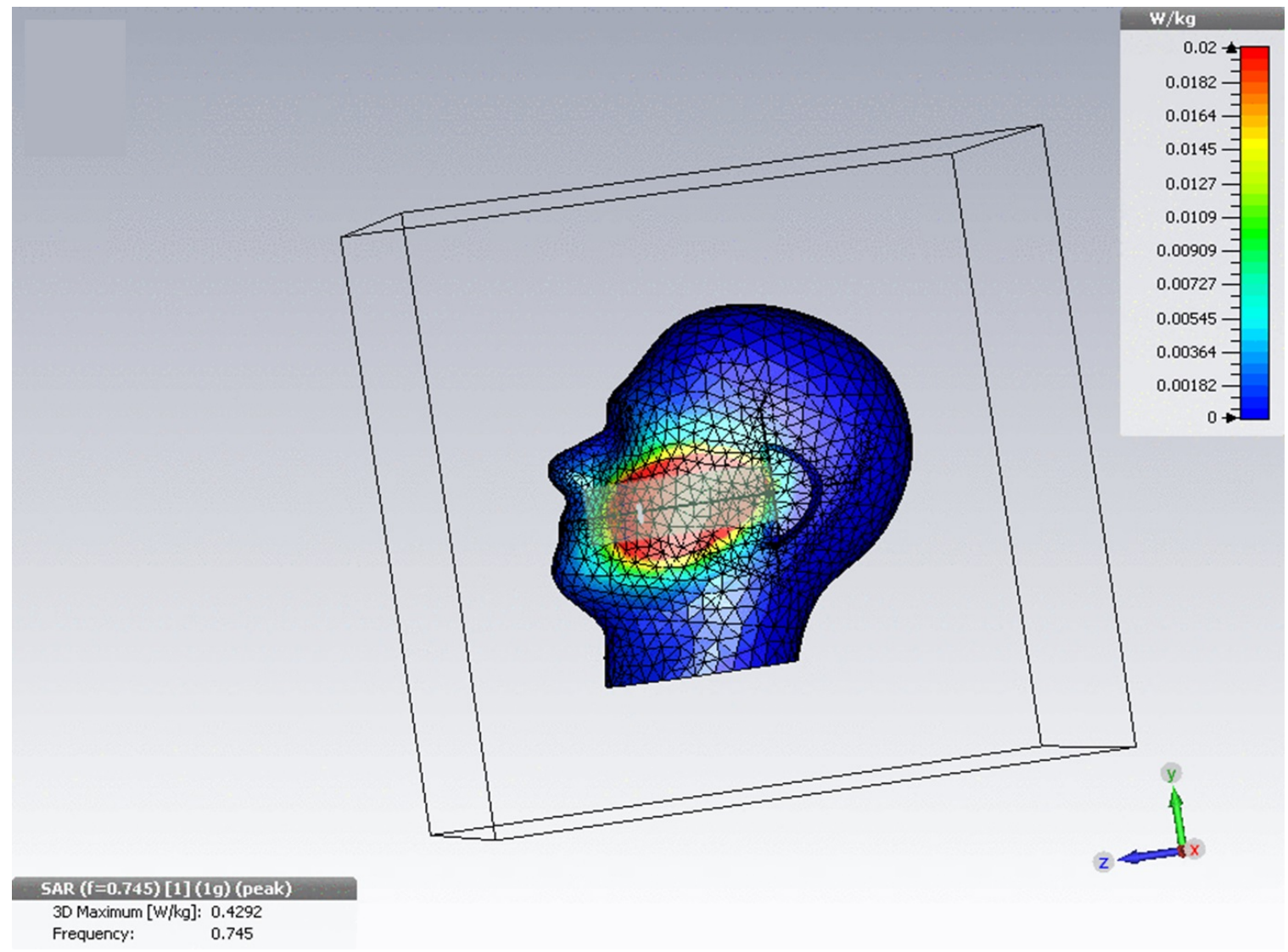

Figure 5.10: Calculated $\mathrm{SAR}=0.43 \mathrm{~W} / \mathrm{Kg}(1 \mathrm{~g}$ tissue) at $0.745 \mathrm{GHz}$ (LTE700) 


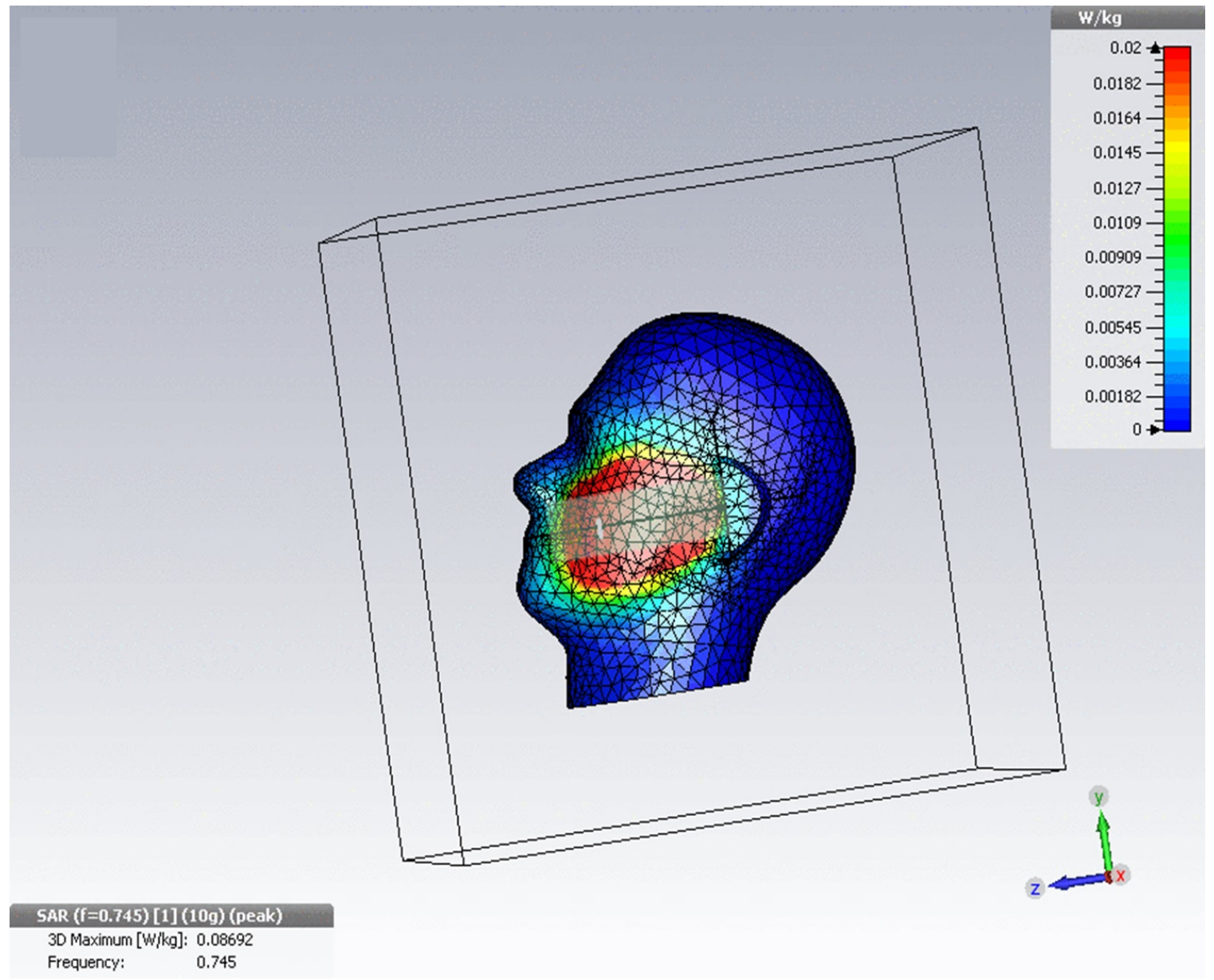

Figure 5.11: Calculated $\mathrm{SAR}=0.09 \mathrm{~W} / \mathrm{Kg}(10 \mathrm{~g}$ tissue) at $0.745 \mathrm{GHz}$ (LTE700) 


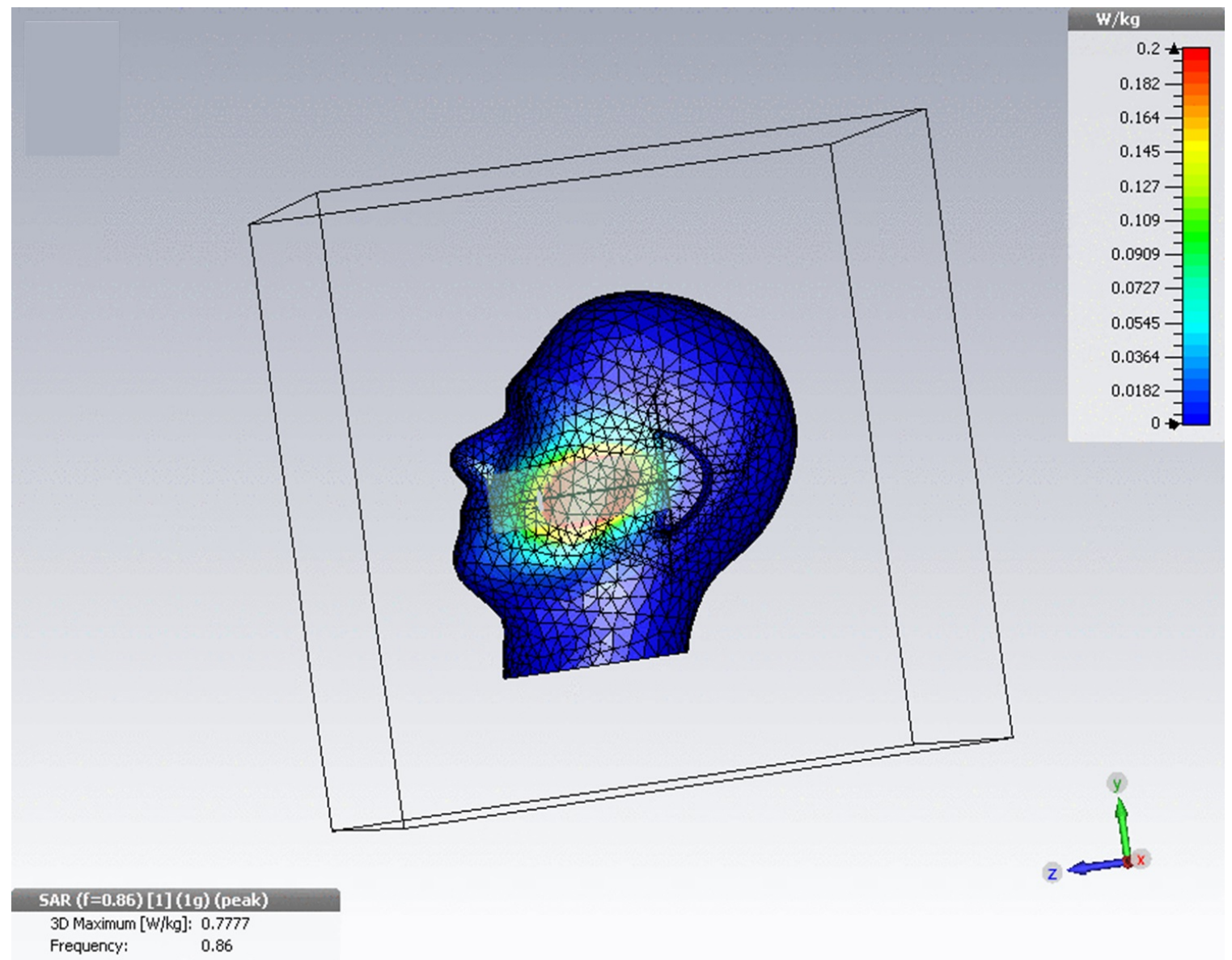

Figure 5.12: Calculated $\mathrm{SAR}=0.78 \mathrm{~W} / \mathrm{Kg}(1 \mathrm{~g}$ tissue $)$ at $0.86 \mathrm{GHz}(\mathrm{GSM}-2 \mathrm{G})$ 


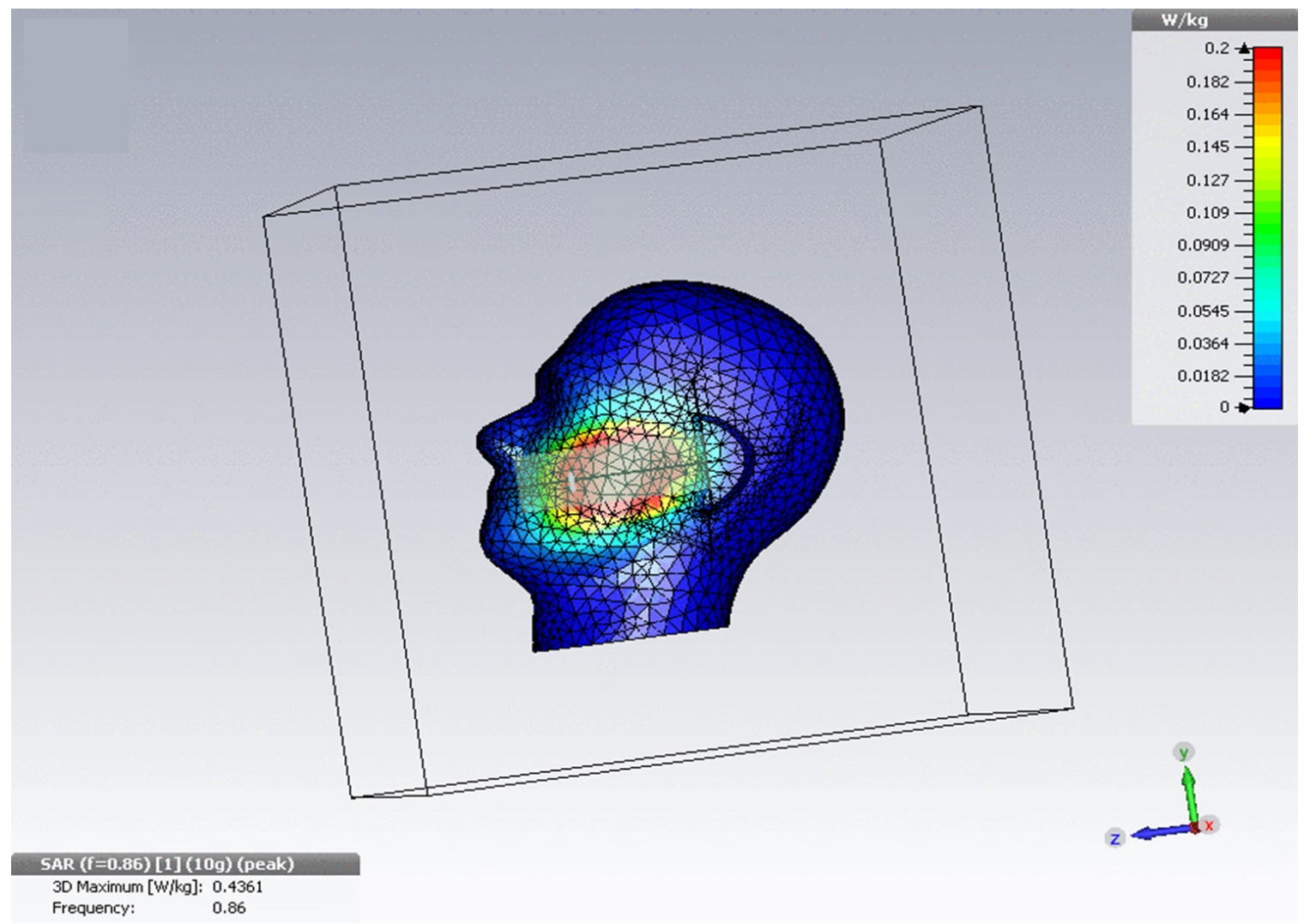

Figure 5.13: Calculated $\mathrm{SAR}=0.44 \mathrm{~W} / \mathrm{Kg}(10 \mathrm{~g}$ tissue $)$ at $0.86 \mathrm{GHz}(\mathrm{GSM}-2 \mathrm{G})$ 


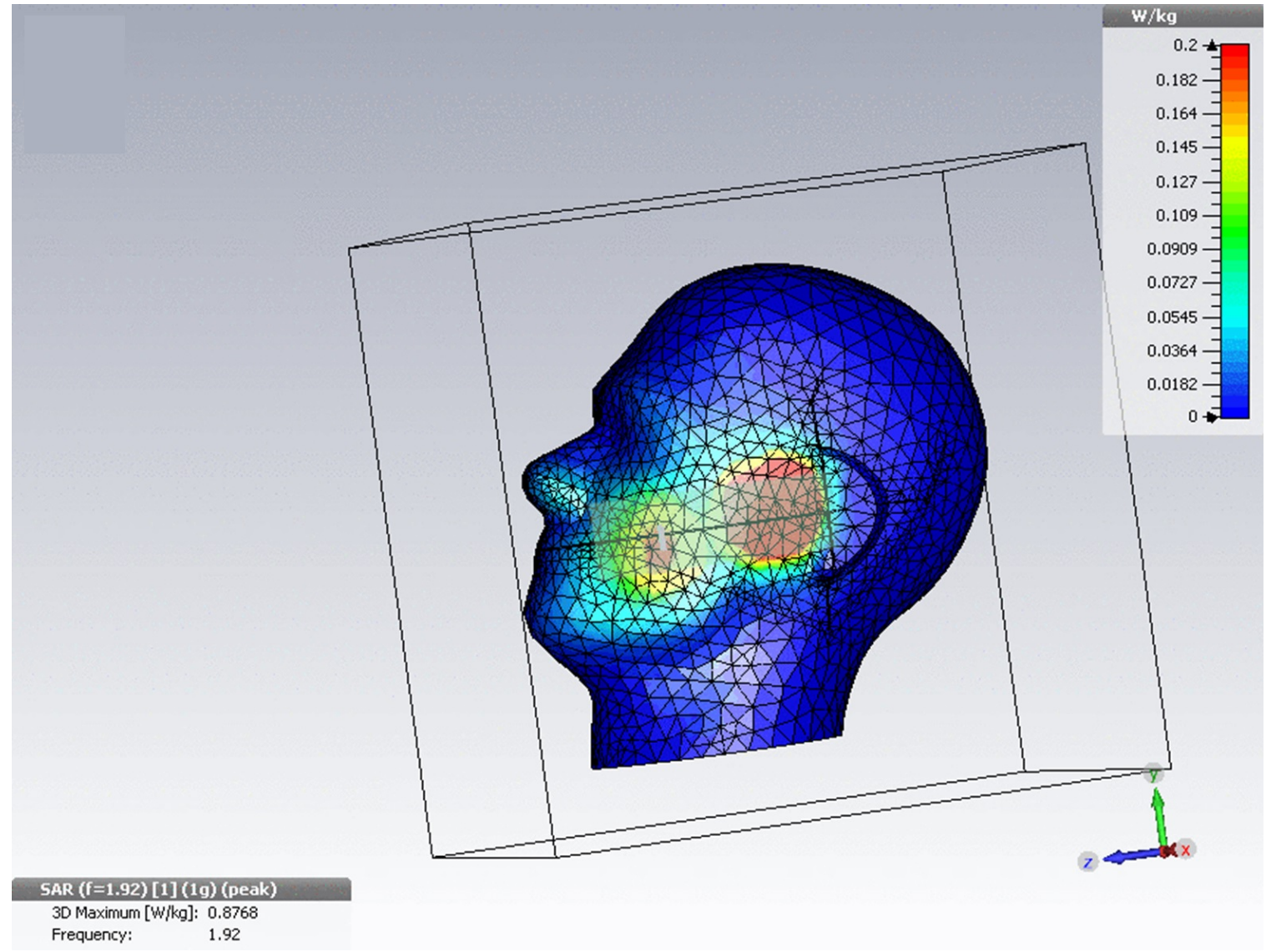

Figure 5.14: Calculated $\mathrm{SAR}=0.88 \mathrm{~W} / \mathrm{Kg}(1 \mathrm{~g}$ tissue) at $1.92 \mathrm{GHz}$ (UMTS-3G) 


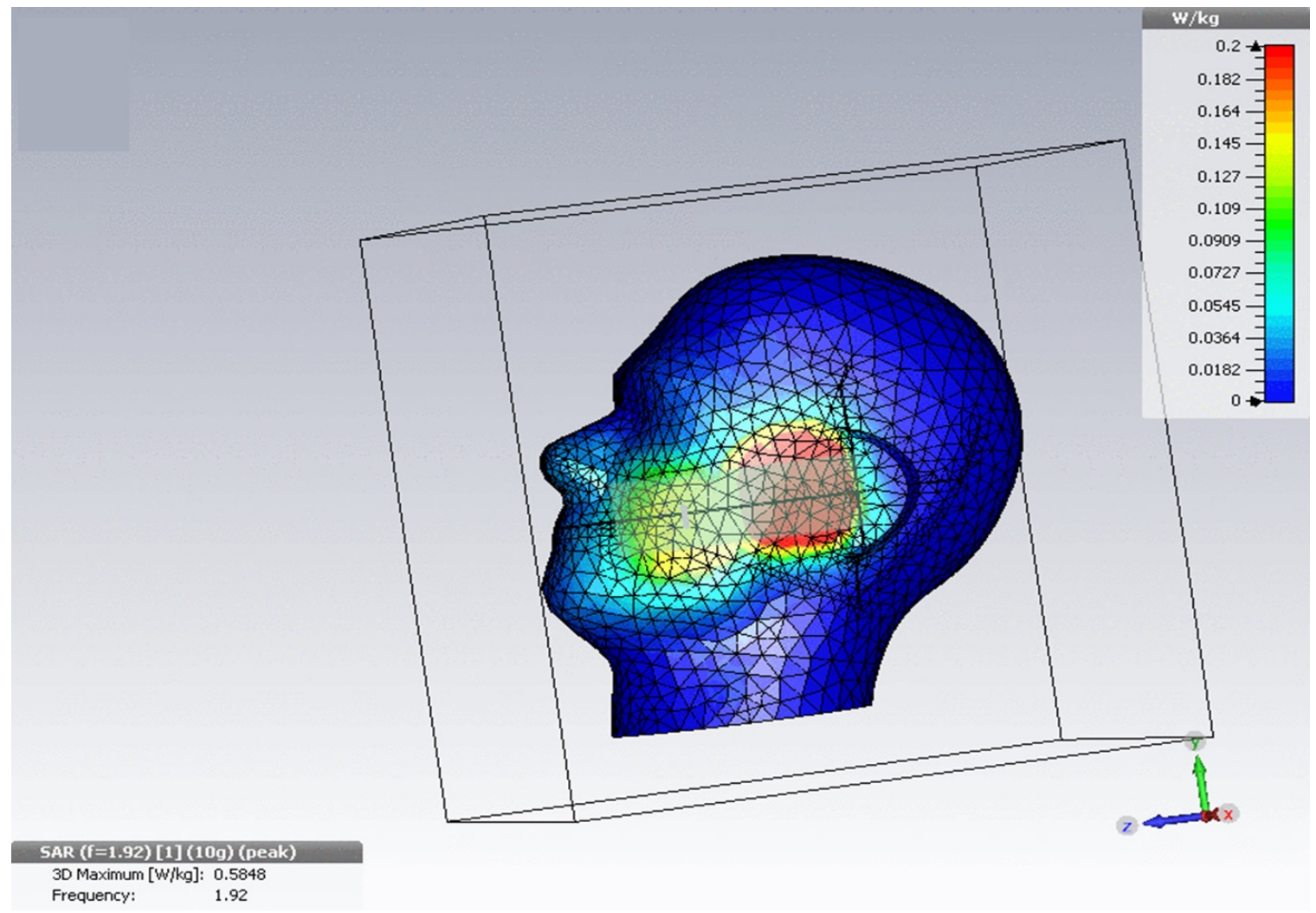

Figure 5.15: Calculated $\mathrm{SAR}=0.58 \mathrm{~W} / \mathrm{Kg}(10 \mathrm{~g}$ tissue) at $1.92 \mathrm{GHz}(\mathrm{UMTS}-3 \mathrm{G})$ 
Page 62 of 74 


\section{Chapter 6: Supplemental Information}

Additional schemes, figures, table and detailed calculation are given in Appendix

\section{Chapter 7: Conclusion}

A polyimide aerogel with low dielectric constant based planar monopole is excited through a slotted capacitive coupling strip and shorted radiating plate through a meandering wire. This proposed antenna covers all the WWAN (LTE/UMTS/GSM) bands along with two GPS and WLAN bands. Due to the low dielectric constant of the polyimide aerogel, gain and radiation efficiency are increased for the entire ultra-wide band. Maximum gain and radiation efficiency of this proposed antenna for the lower band are increased by $0.49 \mathrm{dBi}$ and $3 \%$, respectively, as compared Lee et al, while maximum gain and radiation efficiency for the upper band are increased by $1.15 \mathrm{dBi}$ and $5 \%$, respectively. Specific absorption rate (SAR) is significantly lower than the SAR standard for this low dielectric constant polyimide substrate. Additionally, as this proposed antenna offers an extended wide band from $695 \mathrm{MHz}-2845 \mathrm{MHz}, 5 \mathrm{G}$ operation can also be accommodated for future use in this wide frequency band. 
Page 64 of 74 


\section{References}

[1] Ming Zheng and Hanyang Wang and Yang Hao, Internal Hexa-Band Folded Monopole/Dipole/Loop Antenna With Four Resonances for Mobile Device, IEEE Transactions on Antennas and Propagation, Volume 60, Number 6, June, 2012

[2] Yan-Wu Liang and Hao-Miao Zhou, Small-size LTE/WWAN planar printed antenna for ultrathin smartphone application, Microwave and Optical Technology Letters, Vol. 57, No. 9, September 2015

[3] Park, Y.K. and Sung, Y., A Reconfigurable Antenna for Quad-Band Mobile Handset Applications, IEEE Transactions on Antennas and Propagation, volume 60, number 6, p.3003-p.3006, June, 2012

[4] Wong, Kin-Lu and Chang, Chih-Hua, On-board smallsize printed monopole antenna integrated with USB connector for penta-band WWAN mobile phone, Microwave and Optical Technology Letters, volume 52, number 11, Wiley Subscription Services, Inc., A Wiley Company, 2010

[5] Fang-Hsien Chu and Kin-Lu Wong, Internal Coupled- Fed Dual-Loop Antenna Integrated With a USB Connector for WWAN/LTE Mobile Handset, IEEE Transactions on Antennas and Propagation, volume 59, number 11, p.4215-p.4221, Nov, year 2011 
[6] Min Li and S. W. Cheung and Y. F. Cao and T. I. Yuk, A compact multiband antenna using three monopoles for mobile phone applications, Antennas and Propagation USNC/URSI National Radio Science Meeting, 2015 IEEE International Symposium on, July, 2015.

[7] Wong, Kin-Lu and Lee, Cheng-Tse, Small-size wideband monopole antenna closely coupled with a chip-inductor loaded shorted strip for 11-band WWAN/WLAN/WiMAX operation in the slim mobile phone, Microwave and Optical Technology Letters, volume 53, number 2, p.361-p.366, 2011

[8] Kin-Lu Wong and Chih-Yu Tsai, Small-Size Stacked Inverted-F Antenna With Two Hybrid Shorting Strips for the LTE/WWAN Tablet Device, IEEE Transactions on Antennas and Propagation, volume 62, number 8, p.3962- p.3969, August, 2014

[9] Y.-L. Ban, C.-Q. Lei, J.-H. Chen, S.-C. Sun, Z.-X. Xie and F. Ye, Compact CoupledFed PIFA Employing T-Shaped Monopole with Two Stubs for Eight-Band LTE/WWAN Internal Mobile Phone, Journal of Electromagnetic Waves and Applications, volume 26, number 7, p.973-p.985, 2012

[10] Lee, Cheng-Tse and Wong, Kin-Lu, Uniplanar coupled fed printed PIFA for WWAN/WLAN operation in the mobile phone, Microwave and Optical Technology Letters, volume 51, number 5, 2009

[11] Wong, Kin-Lu and Huang, Chih-Hong, Compact multiband PIFA with a coupling feed for internal mobile phone antenna, Microwave and Optical Technology Letters, volume 50, number 10, p.2487-p.2491, 2008 
[12] Y. Li and Z. Zhang and J. Zheng and Z. Feng and M. F. Iskander, A Compact HeptaBand Loop-Inverted F Reconfigurable Antenna for Mobile Phone, IEEE Transactions on Antennas and Propagation, volume 60, number 1, p.389-p.392, January, 2012

[13] Huang, Hui-Fen and Wu, Jun-Feng, Small-size antenna for seven-band WWAN/LTE mobile handset, Microwave and Optical Technology Letters, volume 57, number 5, p.1098-p.2760, March, 2015

[14] R.A. Bhatti, S.-O. Park, Octa-band internal monopole antenna for mobile phone applications, Electronics Letters, issue 25, volume 44, p.1447-p.1448 December, 2008

[15] Lin, Chia-Ching and Tung, Hao-Chun and Chen, Hong-Twu and Wong, Kin-Lu, A folded metal-plate monopole antenna for multiband operation of a PDA phone, Microwave and Optical Technology Letters, Wiley Subscription Services, Inc., A Wiley Company, volume 39, number 2, p.135-p.138, 2003

[16] Shun-Yun Lin, Multiband folded planar monopole antenna for mobile handset, IEEE Transactions on Antennas and Propagation, volume 52, number7, p.1790- p.1794, July, 2004

[17] Constantine a Balanis, Antenna theory - analysis and design (3rd edition), John Wiley \& Sons, Inc. 2005

[18] Panagopoulos DJ, Johansson O, Carlo GL (2013) Evaluation of Specific Absorption Rate as a Dosimetric Quantity for Electromagnetic Fields Bioeffects. PLoS ONE 8(6), June, 2013

[19] http://www.fcc.gov/encyclopedia/specific-absorptionrate-sar-cellular-telephones 


\section{[20] http://sarvalues.com/what-is-sar-and-what-is-all-the-fussabout}

[21] IEEE Recommended Practice for Determining the Peak Spatial-Average Specific Absorption Rate (SAR) in the Human head from Wireless Communications Devices: Measurement Techniques

[22] Mary Ann B. Meador, Sarah Wright, Anna Sandberg, Baochau N. Nguyen, Frederick W. Van Keuls, Carl H. Mueller, Rafael Rodrguez-Sols and Flix A. Miranda, Low Dielectric Polyimide Aerogels As Substrates for Lightweight Patch Antennas, ACS Applied Materials \& Interfaces, volume 4, number 11, p.6346-p.6353, November, 2012

[23] Full-wave computer simulation technology, CST MWS http://www.cst.com

[24] Bharti et al, Thin Profile Wideband Printed Monopole Antenna for Slim Mobile Handsets Applications, Progress In Electromagnetics Research C, Vol. 57, 149-158, 2015

[25] C. T. Lee and K. L. Wong, Planar Monopole With a Coupling Feed and an Inductive Shorting Strip for LTE/GSM/UMTS Operation in the Mobile Phone, IEEE Transactions on Antennas and Propagation, volume 58, number 7, p.2479-p.2483, July, 2010

[26] Wong, Kin-Lu and Huang, Chih-Hong, Compact multiband PIFA with a coupling feed for internal mobile phone antenna, Microwave and Optical Technology Letters volume 50, number 10, p.1098-p.2760, 2008 


\section{Appendix}

\section{A.1 Evaluation of low dielectric constant Polyimide Aerogel}

Table A.1.1: Properties of the proposed polyimide aerogel for our antenna substrate [22]

\begin{tabular}{|c|c|c|c|c|c|c|c|c|c|c|}
\hline sample & dianhydride & $\begin{array}{l}\text { diamine } \\
(\% \\
\text { DMBZ) }\end{array}$ & $\begin{array}{l}\text { density, } \\
\left(\mathrm{g} / \mathrm{cm}^{3}\right)\end{array}$ & $\begin{array}{c}\text { modulus } \\
(\mathrm{MPa})\end{array}$ & $\begin{array}{l}\text { dielectric } \\
\text { constant, X- } \\
\text { band }\end{array}$ & $\begin{array}{l}\text { loss tangent, } \\
\text { X-band }\end{array}$ & $\begin{array}{c}\text { dielectric } \\
\text { constant, low } \\
\text { freq. }\end{array}$ & $\begin{array}{l}\text { loss tangent, } \\
\text { low freq. }\end{array}$ & $\begin{array}{l}\text { dielectric } \\
\text { constant, Ka- } \\
\text { band }\end{array}$ & $\begin{array}{l}\text { loss tangent, } \\
\text { Ka-Band }\end{array}$ \\
\hline 1 & BPDA & 0 & 0.207 & 13.9 & 1.266 & $8.74 \times 10^{-3}$ & & & & \\
\hline 2 & BPDA & 0 & 0.163 & & 1.2230 & $7.00 \times 10^{-3}$ & & & 1.227 & $7.00 \times 10^{-3} 3$ \\
\hline 4 & BPDA & 0.75 & 0.159 & 43.7 & 1.158 & $4.33 \times 10^{-3}$ & 1.260 & $6.77 \times 10^{-3} 4$ & & \\
\hline 5 & BPDA & 0.75 & 0.108 & & 1.136 & $5.68 \times 10^{-3}$ & & & 1.133 & $1.78 \times 10^{-3} 3$ \\
\hline 6 & BPDA & 0.50 & 0.188 & 33.9 & & & & & 1.214 & $3.37 \times 10^{-3} 3$ \\
\hline 9 & BPDA & 1.00 & 0.131 & 20.1 & 1.159 & $1.10 \times 10^{-3}$ & 1.249 & $1.54 \times 10^{-3} 3$ & & \\
\hline 10 & BTDA & 0 & 0.264 & 6.7 & & & & & & \\
\hline 11 & BTDA & 0.25 & 0.195 & 17.8 & 1.246 & $4.69 \times 10^{-3}$ & & & & \\
\hline 12 & BTDA & 0.50 & 0.196 & & 1.249 & $4.13 \times 10^{-3}$ & & & & \\
\hline 13 & BTDA & 1.00 & 0.210 & 102. 3 & 1.280 & $4.13 \times 10^{-3}$ & & & 1.289 & $2.68 \times 10^{-3} 3$ \\
\hline 14 & BTDA & 0.75 & 0.197 & 56.2 & 1.239 & $4.60 \times 10^{-3}$ & 1.356 & $1.04 \times 10^{-3} 3$ & & \\
\hline
\end{tabular}




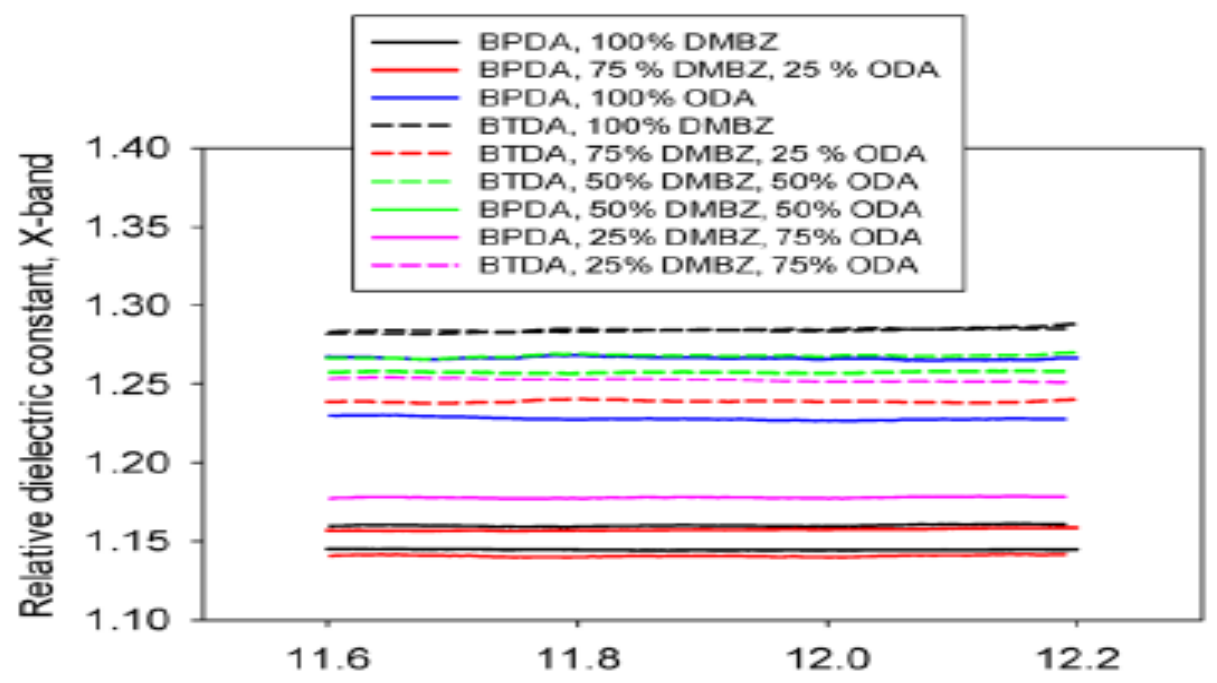

a)

Frequency, $\mathrm{GHz}$

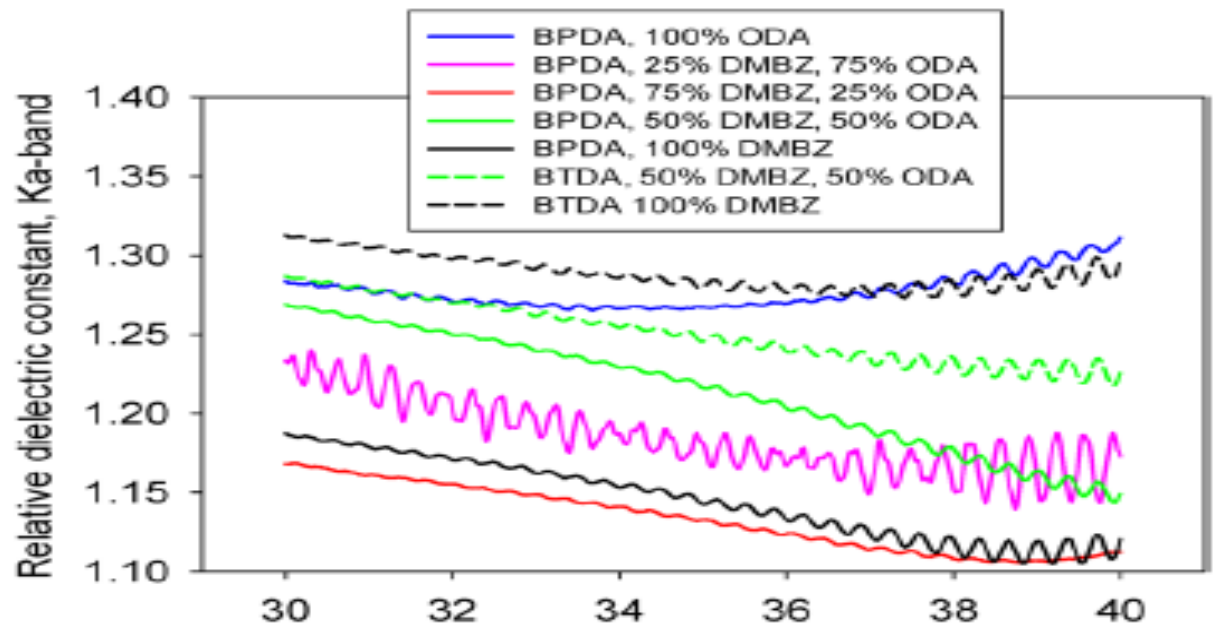

b)

Frequency, GHz

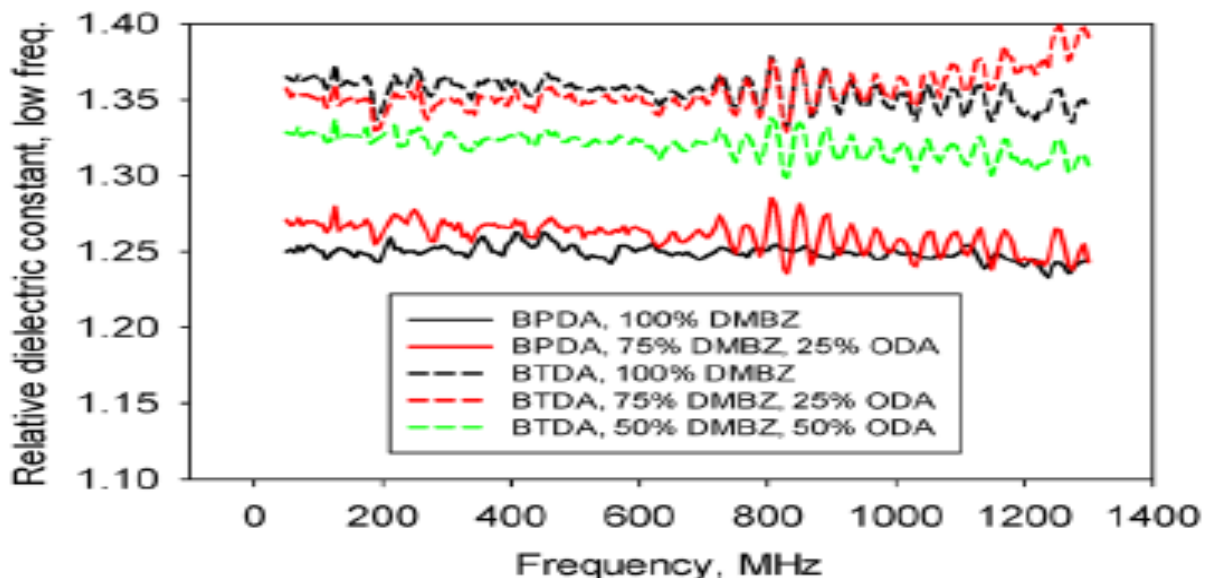

c)

Frequency, $\mathrm{MHz}$

Figure A.1.1: Dielectric constant of the polyimide aerogel for three bands [22] 


\section{A.2 Derivation of Specific Absorption Rate for the Electromagnetic} Fields effects in Biological tissue [18]:

Specific absorption rate can be defined as:

$$
S A R=\frac{d P}{d m}
$$

and neglecting thermal losses, the absorbed electric power can be expressed as the power of a generated internal electric current within the tissue/organ, $d P=d \Psi \cdot i$, where $d \Psi$, is an incremental voltage generated within the tissue/organ by the external electromagnetic field/wave corresponding to the absorbed incremental power $d P$, and $i$ the current intensity - across an area $S$ vertical to the current - corresponding to the incremental voltage $d \Psi$. Thereby, Eq. (A.2.1) becomes:

$$
S A R=\frac{d \Psi \cdot i}{d m}
$$

By multiplying both the numerator and the denominator by the area $S$, we get

$$
\begin{aligned}
& S A R=\frac{d \Psi \cdot i \cdot S}{d m \cdot S}, \text { or } \\
& S A R=\frac{d \Psi \cdot j \cdot S}{d m}
\end{aligned}
$$

where $j=\frac{i}{S}$ is the corresponding current density generated within the tissue/organ. 
Since $d \Psi=-E \cdot d r$, where $E$ the generated internal electric field and $d r$ a charge displacement in the direction of the generated current $i$, we get (neglecting the minus sign):

$$
S A R=\frac{E \cdot d r \cdot j \cdot S}{d m}
$$

But $d r S=d V$, is the volume corresponding to the area $S$ and the charge displacement $d r$, containing the mass $d m$, and $\frac{d m}{d V}=\rho$ is the tissue/organ density assuming it has a constant value. Thereby, eq. (A.2.3) becomes:

$$
S A R=\frac{j \cdot E}{\rho}
$$

Finally, using the Ohm's law: $j=\sigma E$,

$$
S A R=\frac{\sigma \cdot \mathrm{E}^{2}}{\rho}
$$

It is obvious that in the above operations, the quantities $i, j, S, E, \rho$, and $\sigma$ are assumed to be constant within the biological tissue/organ. 


\title{
A.3 Permission from Mary Ann B. Meador, Sarah Wright, Anna
}

\section{Sandberg, et al, Low Dielectric Polyimide Aerogels as Substrates for Lightweight Patch Antennas, 2012 American Chemical Society}

\author{
Title: Low Dielectric Polyimide Aerogels \\ As Substrates for Lightweight \\ Patch Antennas \\ Author: \\ Mary Ann B. Meador, Sarah \\ Wright, Anna Sandberg, et al \\ Publication: Applied Materials \\ Publisher: American Chemical Society \\ Date: Nov 1, 2012 \\ Copyright (c) 2012, American Chemical Society
}

Logged in as:

M Mahfuzur Rahman

Account $\#$ :

3000797710

LOGOUT

\section{PERMISSION/LICENSE IS GRANTED FOR YOUR ORDER AT NO CHARGE}

This type of permission/license, instead of the standard Terms \& Conditions, is sent to you because no fee is being charged for your order. Please note the following:

- Permission is granted for your request in both print and electronic formats, and translations.

- If figures and/or tables were requested, they may be adapted or used in part.

- Please print this page for your records and send a copy of it to your publisher/graduate school.

- Appropriate credit for the requested material should be given as follows: "Reprinted (adapted) with permission from (COMPLETE REFERENCE CITATION). Copyright (YEAR) American Chemical Society." Insert appropriate information in place of the capitalized words.

- One-time permission is granted only for the use specified in your request. No additional uses are granted (such as derivative works or other editions). For any other uses, please submit a new request.

If credit is given to another source for the material you requested, permission must be obtained from that source.

Figure A.3.1: This letter is for Table A.1.1 and Figure A.1.1 


\section{A.4 Permission from Panagopoulos DJ, Johansson O, Carlo GL (2013) Evaluation of Specific Absorption Rate as a Dosimetric Quantity for Electromagnetic Fields Bioeffects. PLoS ONE 8(6): e62663.}

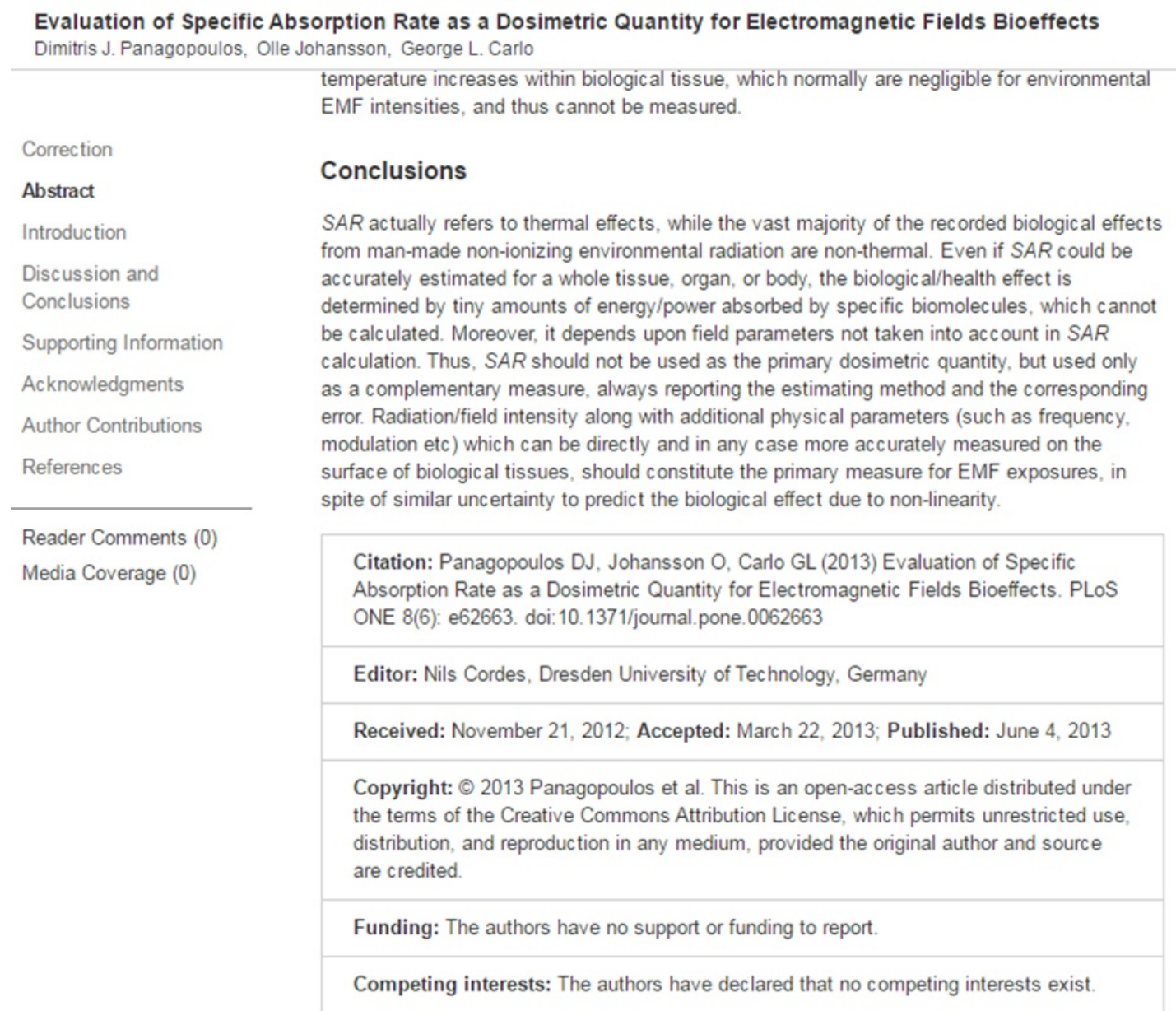

Figure A.4.1: This letter is for Appendix A.2 Derivation of Specific Absorption Rate for the Electromagnetic Fields effects in Biological tissue 